
EchoGéo
44 | 2018
Les valorisations territoriales et touristiques du street art

\title{
Le street art à Naples
}

Entre pratiques informelles et instrumentalisation de l'art urbain : discours et stratégies d'acteurs

\section{Christine Salomone}

\section{(2) OpenEdition}

\section{Journals}

Édition électronique

URL : https://journals.openedition.org/echogeo/15640

DOI : $10.4000 /$ echogeo. 15640

ISSN : 1963-1197

\section{Éditeur}

Pôle de recherche pour l'organisation et la diffusion de l'information géographique (CNRS UMR 8586)

Référence électronique

Christine Salomone, "Le street art à Naples », EchoGéo [En ligne], 44 | 2018, mis en ligne le 31 juillet 2018, consulté le 31 juillet 2021. URL : http://journals.openedition.org/echogeo/15640 ; DOI : https:// doi.org/10.4000/echogeo.15640

Ce document a été généré automatiquement le 31 juillet 2021.

EchoGéo est mis à disposition selon les termes de la licence Creative Commons Attribution - Pas d'Utilisation Commerciale - Pas de Modification 4.0 International (CC BY-NC-ND) 


\title{
Le street art à Naples
}

\author{
Entre pratiques informelles et instrumentalisation de l'art urbain : \\ discours et stratégies d'acteurs
}

\section{Christine Salomone}

1 Le street art suscite en Europe, un véritable engouement à l'origine de nombreuses initiatives culturelles ou touristiques. Symbole de créativité et de dynamisme, ces pratiques artistiques ne génèrent toutefois pas systématiquement une mise en tourisme. Cet art urbain oscille entre pratique populaire contestataire et art légitime officialisé (Genin, 2008). Son identification est difficile, voire controversée, tant les contours de sa définition demeurent flous (Genin, 2015). Pour étudier le rôle du street art dans la régénération urbaine, on peut dès lors vouloir questionner les stratégies des acteurs et des lieux ainsi valorisés. L'article se propose d'étudier le cas d'une métropole du sud de l'Italie, Naples, confrontée depuis les années 1990 à une véritable effervescence artistique (Froment, 2010). Aux côtés des initiatives officielles valorisant l'art contemporain, des interventions artistiques plus spontanées liées au street art sont aussi anciennes et enracinées, révélant la pluralité des formes d'expression urbaine de l'art contemporain et des logiques spatiales associées.

Depuis peu, la valorisation de l'art urbain revêt une dimension touristique mise en avant par certains acteurs, notamment associatifs. En effet, dans un contexte d'austérité frappant les villes d'Europe du Sud, la politique culturelle à Naples est largement dévolue à la société civile. La ville apparaît comme un laboratoire d'expérimentations sociales en faisant émerger de nouvelles formes de gouvernance urbaine et de nouveaux acteurs (le «tiers secteur ») participant à sa renaissance par la culture (Froment, 2015). Si la littérature scientifique a beaucoup documenté le tournant culturel des projets urbains, le rapport aux logiques informelles de production dans le champ artistique et de gouvernement des espaces urbains a été moins étudié (Froment, 2016). La culture est un champ d'étude fécond à analyser en particulier à cause de l'ambiguité des rôles qui lui sont conférés. Le street art contribue à renforcer l'attractivité de Naples après les années difficiles de la «crise des déchets » (2007-2011) (Salomone, 2015). La commune, en décembre 2016, reconnaît ainsi officiellement le phénomène comme une nouvelle forme d'expression de la jeunesse et entend en 
valoriser les manifestations sur son territoire. Cette initiative est peut-être le point départ d'un art urbain " organisé ", mais elle interroge également le sens et les moteurs de cette créativité urbaine portée par des acteurs variés, individuels ou associatifs. Étudier le rapport entre stratégies d'acteurs et discours intervenant dans ce champ de la culture marqué par des pratiques informelles permet de questionner le jeu de pouvoir qui s'établit dans le gouvernement urbain.

Dans quelle mesure la difficile institutionnalisation, pérennisation et valorisation du street art, d'une activité née comme transgressive, participe au renouvellement urbain de quartiers en déshérence ? N'est-elle pas dépendante à la fois du contexte local, des objectifs et stratégies recherchés par les acteurs et des espaces dans lesquelles elle s'inscrit?

4 Après avoir rappelé les rapports entre art, tourisme et renouvellement urbain et présenté les enjeux de l'usage du street art dans les politiques urbaines, l'article questionne la présence et la diffusion de cet art urbain à la fois dans une marge du centre historique (l'aire Vergini-Sanità) et dans un quartier plus périphérique et moins touristique (Ponticelli). Comment le "projet street art » apparu récemment dans ces deux quartiers est-il utilisé, voire instrumentalisé, par les acteurs du territoire au service de politiques urbaines?

5 La méthodologie est centrée sur l'étude des logiques d'acteurs et l'analyse de leurs discours. Par le biais d'une série d'entretiens semi-directifs effectués entre 2015 et 2018 et grâce à un suivi régulier des acteurs privés et publics impliqués dans la valorisation du street art, nous cherchons à comprendre les stratégies et discours affichés par ceux qui produisent le street art (les artistes), et ceux qui le valorisent ou le développent: acteurs privés, associatifs et acteurs institutionnels ${ }^{1}$. Trois entretiens effectués auprès d'artistes napolitains en 2017 et 2018 tentent de cerner leur démarche artistique ; huit représentants d'associations ou des opérateurs culturels témoignent des formes variées prises par cette valorisation du street art ; quatre responsables, élus et fonctionnaires de la commune dans les divers assessorats (Urbanisme, Assessorat aux jeunes, Tourisme et Culture) révèlent l'importance accordée à cet art urbain par les acteurs institutionnels.

6 Pour des raisons matérielles liées aux conditions de l'enquête, l'article explore peu la réception du street art auprès de la population ou des touristes ${ }^{2}$. L'offre touristique étant très récente, elle donne peu la possibilité d'en appréhender, avec suffisamment de recul, la portée ${ }^{3}$. Des échanges informels ont été menés auprès de certains habitants des quartiers concernés et certains parcours de visite ont été effectués in situ. D’autres corpus sont aussi mobilisés (site internet, blogs, presse locale) sans oublier les réseaux sociaux ${ }^{4}$ (Facebook et Tripadvisor), lieu d'expression des artistes et vitrine de cet engouement porté à l'art urbain, pour saisir la diversité des discours à l'œuvre.

\section{Street art, tourisme et renouvellement urbain}

7 Si le terme lui-même s'est imposé tardivement pour désigner une pratique née au cours du XXe siècle (dès les années 1960), il renvoie néanmoins à une culture commune, une véritable culture visuelle qui s'est propagée à travers le monde. Pratique performative d'essence éphémère, le terme englobe une myriade de conduites spontanées et transgressives, longtemps considérées comme des actes de vandalisme (McAuliffe, 2012). Il obéit à une visée artistique et doit être distingué du tag, simple signature de l'auteur. Dans une conception large, il désigne «tout type d'inscriptions urbaines 
(gravures, biffure, graff, tag, sticker, affiche, mosaïque, peinture murale » (Genin, 2009, p. 24). On distingue le street art du « style writing », du graffiti. Ce dernier met en avant la virtuosité technique s'adressant à un public d'initiés ou d'experts alors que le street art est davantage axé sur le contenu et privilégie la lisibilité dans un but d'accessibilité élargie (Blanché, 2015). Dès son origine, cet art urbain se développe dans des espaces à l'abandon, nombreux dans les villes frappées par la désindustrialisation (Blanchard, 2017), et les productions privilégient les quartiers en mutation comme espace d'expression (Kullmann, 2015).

8 Pour interroger le street art et la façon dont il est mobilisé dans les politiques culturelles accompagnant la régénération urbaine, il est nécessaire de replacer ces évolutions dans un contexte plus général (Djament-Tran, 2014). Une pluralité de termes est mobilisée pour qualifier ce processus de transformation en fonction des pays et des stratégies adaptées : régénération urbaine en Grande-Bretagne, requalification urbaine en Italie, renouvellement urbain en France ${ }^{5}$. Dans tous les cas, cela suppose une reconstruction de la ville sur elle-même en accordant de l'importance à la qualité des espaces (Novarina et Pucci, 2004). La fonction culturelle est devenue une composante majeure de la régénération urbaine pour de nombreuses villes sud-européennes, garante d'une redynamisation économique et sociale et d'une image urbaine forte (Rodrigues-Malta, 2001). Dans un contexte de compétition, les politiques se concentrent d'abord sur les " grands projets » des centres-villes, jouant un rôle de vitrine pour l'économie locale : grands musées, architectures prestigieuses ou encore organisation d'événements internationaux (Ingallina et Park, 2005). À partir des années 1990, la mobilisation de la culture s'étend à d'autres champs de l'action publique locale et sert de levier à de nombreux projets de requalification urbaine (Andres et Ambrosino, 2008) visant la transformation physique et sociale d'espaces déprimés (Bianchini et Parkinson, 1993). La ressource culturelle est mobilisée voire instrumentalisée dans les politiques urbaines, comme un outil de renouvellement urbain (Vivant, 2009). Cette dimension occupe une place centrale au sein des politiques urbaines avec comme horizon, le référentiel de la ville créative (Génard, 2014). La mobilisation de la culture devient un enjeu central du rapport de force entre les acteurs et invite à repenser les jeux de pouvoir (Froment, 2016). Les territoires urbains sont en effet particulièrement adaptés à l'expression de la singularité et de la créativité (Hall, 1998). Le recours à l'art contemporain s'impose comme l'une composante des politiques urbaines: enjeu et moyen de l'autopromotion des villes (Gilabert, 2004). On assiste à l'émergence de «nouveaux territoires de l'art» (Lextrait et Kahn, 2004) tels les friches ou les squats, participant à ce nouveau cycle de développement des villes. Dès lors, le street art se mue en un véritable outil de valorisation des espaces en donnant une dimension créative et dynamique à l'espace dans lequel les œuvres s'inscrivent (Talamoni, 2015). L'engouement pour cet art urbain correspond à un processus de métropolisation par l'art et la culture (Gresillon, 2014). La mise en scène et en visibilité des espaces de la création obéit ainsi à des fins de marketing urbain (Kullmann, 2015) et sert l'esthétisation des territoires (Gravari-Barbas, 2009).

9 En Italie, l'intérêt pour le street art se diffuse dès les années 1980 chez des observateurs passionnés ${ }^{6}$ et donne naissance aux premières expositions. Le phénomène se répand dans les années 1990 comme une pratique alternative et transgressive en lien avec le rôle joué par les centres sociaux occupés des grandes métropoles (Milan, Rome, Naples) contribuant à la diffusion de la culture hip hop et à celle des graffitis (Tomassini, 2012). 
La connaissance des œuvres et la diffusion des pratiques artistiques s'opèrent également grâce aux "street shops » et aux revues spécialisées, les «fanzines » (fanatic magazines) autoproduites par les artistes et photocopiées (Tagliazucchi, 2013). Les œuvres occupent les murs d'espaces abandonnés à Milan comme à Rome, graffitis et street art se diffusent principalement dans les grandes villes du Nord ou du Centre. Les premières règlementations et campagnes anti-graffitis apparaissent à la fin des années 1990, de nombreuses villes privilégient des politiques très répressives (Milan). D’autres, comme Turin, s'engagent précocement dans une politique de reconnaissance et de promotion de l'art urbain à travers des événements, des lieux dédiés et des expériences participatives. Turin, comme Naples ont adopté des initiatives importantes en faveur de l'art public associées à la programmation urbanistique (« Projet spécial Périphéries » en 1997 à Turin) ; l'art y est envisagé comme un instrument de régénération urbaine et de renforcement du lien social. Il est aussi utilisé pour consolider l'image de la ville et servir son attractivité (Antonioli, 2015, p. 217).

10 Ainsi, le street art se développe en suivant des dynamiques contrastées, voire opposées. C. Genin rappelle dans un article (2015) les paradoxes de ce phénomène à l'extension planétaire, son hétérogénéité, ses diverses motivations mais aussi son intégration aux marchés. Les travaux réalisés par E. Vivant $(2007,2009)$ distinguent les pratiques culturelles «in» et celles «off»: les pratiques formelles et reconnues par les institutions et les pratiques artistiques informelles, construites en marge de la légalité, initiées par des acteurs associatifs, culturels ou artistiques sans soutien commercial ou institutionnel. Le street art témoigne de l'évolution de la création culturelle, de ses formes, des mélanges de genre et de la reconnaissance par les institutions culturelles de cette "sous-culture». Les pratiques artistiques "off » peuvent être l'expression d'une créativité endogène voire contestataire; elles sont caractérisées par leur évanescence, leur inconsistance et peuvent disparaître à tout moment (Vivant, 2007). La reconnaissance et la légitimation du street art aboutissent à sa mise en visibilité et sa commercialisation : il s'expose dans des galeries spécialisées à New-York dès les années 1980, à Paris dans les années 1990 (Liebaut, 2012, p. 159). Certains craignent la «muséification » controversée des œuvres, en contradiction avec la nature même de cet art urbain inscrit dans l'espace public et accessible à tous.

Pourtant sa place dans les politiques urbaines demeure assez contradictoire: les municipalités continuent à mener des politiques d'effacement et de répression des tags et des graffitis, tout en préservant des espaces dédiés à un street art considéré comme patrimoine local dans certains quartiers (Blanchard, 2017). L'institutionnalisation de cette nouvelle forme d'art urbain brouille les frontières entre culture savante et culture populaire, ce que traduit aussi l'évolution des différentes pratiques et des productions culturelles avec la promotion de l'art contemporain. Il est présenté comme " démocratique » car il livre une expérience artistique visuelle gratuite, offerte à tous les citadins (Kullmann, 2015). La promotion du street art dans les politiques culturelles est aussi un moyen de toucher les jeunes. Le street art, pratique identifiée comme transgressive, participe à la fabrique de la ville créative. Les projets culturels innovants dotés de cette dimension participative dynamisent l'image des villes en mutation (Saez, 2014). Dans les quartiers défavorisés où il se déploie, il encourage cette démocratisation culturelle à travers des ateliers participatifs. L'action culturelle est alors utilisée en complément de l'action sociale (Milliot, 2000). 
Pour mesurer les effets de ces politiques culturelles sur la revalorisation des quartiers, il faut rappeler que la présence des artistes dans les villes dites « créatives » est perçue comme un indice de transformation des espaces urbains, voire de gentrification ${ }^{7}$ (Clerval et Fleury, 2009). La présence des artistes est alors une première étape dans la revalorisation de certains quartiers, ils investissent des lieux marginalisés à faible valeur foncière et les rendent visibles. Les politiques culturelles accompagnent et amplifient les effets de la gentrification. Le développement du tourisme et de pratiques culturelles accompagne ce processus de gentrification. Le street art est ainsi un outil au service de la mise en tourisme des territoires. Il favorise l'émergence d'un tourisme présenté comme créatif (Gombeau, 2011). L'activité elle-même est désormais considérée comme une « industrie créative » dans le cadre de la nouvelle économie de la culture (Throsby, 2001), la culture étant perçue comme étant à la fois une ressource et un produit du tourisme. Parmi les facteurs favorisant l'émergence de ce tourisme créatif, Richards et Wilson (2006) insistent sur la participation des consommateurs à la production, à la création de leurs expériences de consommation. Le tourisme créatif est alors fondamentalement un tourisme expérientiel (Richards, 2011) où le principe du plaisir est essentiel dans la satisfaction apportée par l'expérience de consommation (Bourgeon et Bouchet, 2007). Les émotions, les sensations, les affects sont au cœur de l'expérience vécue comme pour les balades urbaines proposées à Vitry-sur-Seine (Talamoni, 2015). Ce tourisme créatif suppose l'expérience d'activités spectaculaires, celle d'espaces créatifs et/ou la co-production d'activités créatives. Les touristes contemporains recherchent en effet « des espaces publics alternatifs » (Richards, 2011) ou des "quartiers urbains créatifs» (Pappalepore et al., 2010). Le Nord-Est parisien promu par les acteurs institutionnels apparaît comme un espace "branché", authentique et révélateur des cultures urbaines. Ainsi, les flux touristiques se diffusent vers de nouveaux espaces, investissant de nouvelles zones intra-muros ou des quartiers plus périphériques, comme les franges des métropoles et les quartiers de banlieue. L'objectif assigné au street art par les acteurs institutionnels est d'offrir aux habitants un nouveau regard sur leur ville, mais aussi de séduire les touristes. Le web et les réseaux sociaux sont un véhicule de propagation des œuvres et de reconnaissance médiatique des artistes. Ils servent indirectement à la mise en visibilité des territoires et à leur promotion touristique. Pour les grandes métropoles, investir le champ du street art contribue au renouvellement de leur offre touristique, présentée comme alternative et signe de créativité urbaine. Outil de marketing urbain, il participe à la mise en tourisme de la ville et des quartiers plus périphériques. Ne permet-il pas aussi à des villes plus secondaires comme Naples de s'affirmer dans un contexte devenu plus concurrentiel?

\section{Naples ou la difficile pérennisation / valorisation du street art?}

\section{Naples, un laboratoire d'expression de l'art contemporain}

Naples semble être un terrain favorable à l'épanouissement de telles pratiques spontanées. Métropole durement frappée par la désindustrialisation et les difficultés économiques à partir des années 1970-1980, elle a fait de l'art et la culture un levier de développement et un outil de changement d'image, pour une ville en quête de 
modernité et de normalisation (Cattedra et Memoli, 2003). Sa « renaissance » dans la décennie 1990 repose notamment sur l'utilisation de l'art contemporain (Palestino, 2003). Le maire de l'époque A. Bassolino, dans le cadre du projet Gli Annali delle Arti, multiplie les initiatives : expositions d'artistes dans l'espace urbain et mise en scène des espaces publics; réalisation des «stations de l'art » de la ligne de métro 1 où plus de 200 œuvres d'art contemporain contribuent à un marketing urbain ; implantation d'un grand équipement culturel consacré à l'art contemporain en 2005 dans un quartier populaire proche du centre antique (Froment, 2003a, 2010).

Cette présence de l'art contemporain est attestée à Naples bien avant les initiatives de la nouvelle équipe municipale autour de projets urbanistiques $^{8}$ ou encore d'interventions artistiques alternatives. Ainsi, Ernest Pignon-Ernest, précurseur du street art, explore et valorise les ruelles du centre historique durant son séjour entre 1988 et 1995 et tente de saisir l'essence du lieu en apposant ses images sur les murs, fondues dans l'architecture urbaine (Velter, 2014). Les politiques culturelles mises en place reposent à la fois sur une valorisation du patrimoine existant et une réhabilitation des lieux symboliques (Froment, 2003b). La ville réutilise des recettes expérimentées par d'autres villes italiennes et européennes dès les années 1980. Les objectifs recherchés par les acteurs sont à la fois d'ordre esthétique (améliorer le cadre urbain) et civique (nécessité de prendre soin de son territoire). Cela participe d'un discours officiel sur le rétablissement du "sens de la communauté » locale et de la reconquête d'un orgueil civique à travers les politiques de réhabilitation du centreville. Ce discours est relayé par d'autres acteurs non institutionnels, notamment issus des milieux intellectuels et bourgeois, tels la Fondation Napoli $99^{9}$, qui collaborent avec la commune (Rossi, 2009). Cette dernière s'engage dans des projets de restauration et de valorisation du patrimoine bâti dès les années 1980 (lancement de l'opération "Monuments porte ouvertes" en 1992) et de sensibilisation à l'objet patrimonial ("L'école adopte un monument »). Ce discours s'ancre dans une longue tradition d'une approche culturaliste du sous-développement du Mezzogiorno et de ses classes populaires napolitaines et $d u$ "mythe presque atavique de son absence de sens civique »(Petrillo, 2011, p 47).

\section{Une floraison d'initiatives spontanées et informelles}

Si l'art contemporain est mis en scène et valorisé dès les années 1990, le street art ne jouit pas encore d'une reconnaissance officielle et il est cantonné à une pratique informelle, transgressive et souvent clandestine. La ville apparaît comme un laboratoire d'expériences innovantes, riche d'interventions menées dans les espaces interstitiels, marginaux et périphériques. 


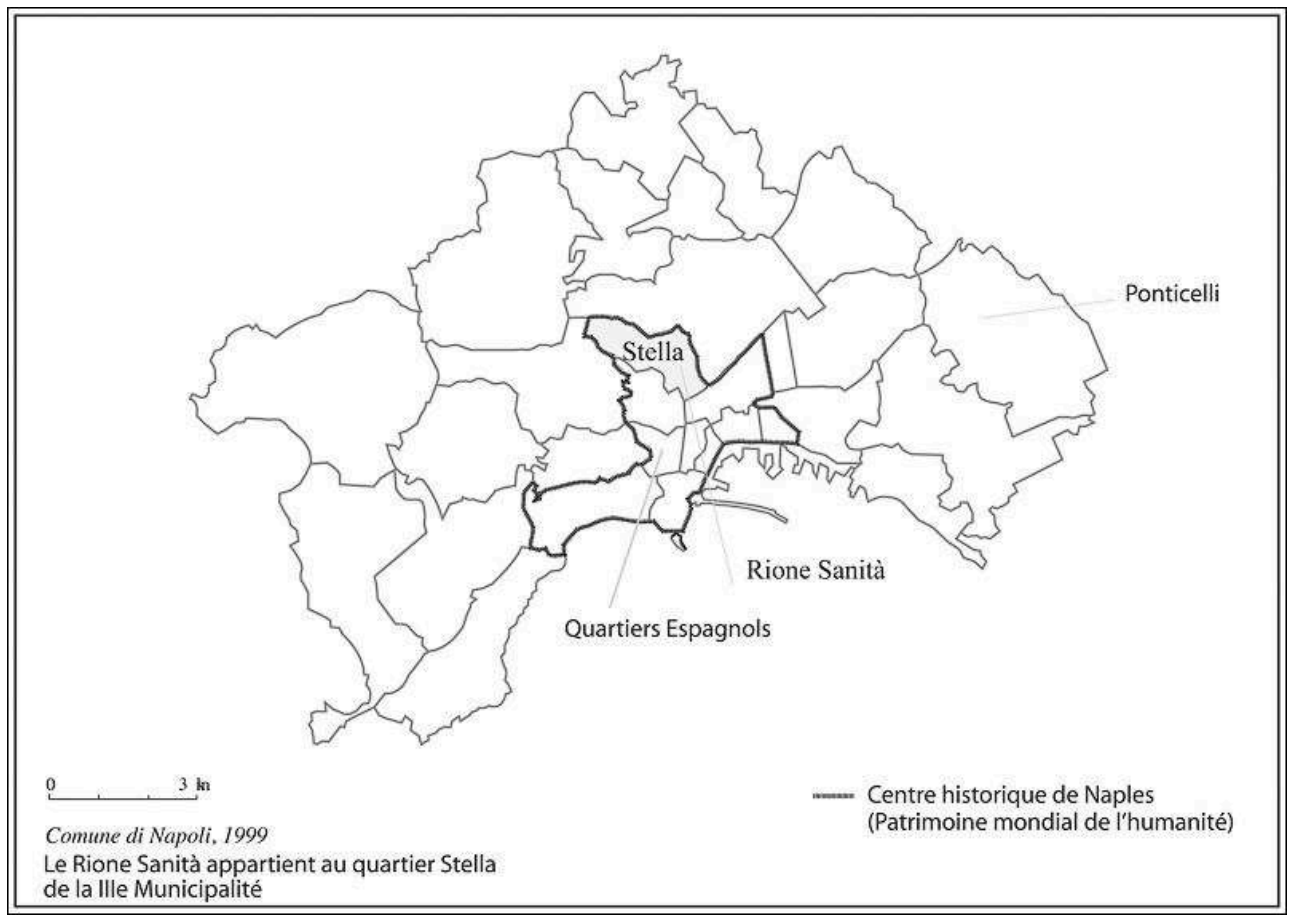

Elle a su, avec ses contradictions, attirer précocement des artistes de renom: des œuvres d'Ernest Pignon-Ernest précurseur, d'Alice Pasquini ${ }^{10}$ à proximité de la Calata Trinita Maggiore à la " Vierge au pistolet » de Bansky ${ }^{11}$ située sur la place Gerolomini, ou plus récemment aux œuvres des Français C215, Mr Chat ${ }^{12}$ ou Zilda ${ }^{13}$ dans des quartiers centraux ou plus périphériques (voir illustrations 2 à 5 présentant les interventions de street artistes étrangers dans le centre historique de Naples). En dépit de la renommée des artistes, ces œuvres n'ont pas bénéficié initialement d'une réelle valorisation touristique par les acteurs officiels, tout au plus s'est-on récemment inquiété de leur protection et de leur sauvegarde ${ }^{14}$. 
Illustration 2 - CEuvre de Zilda

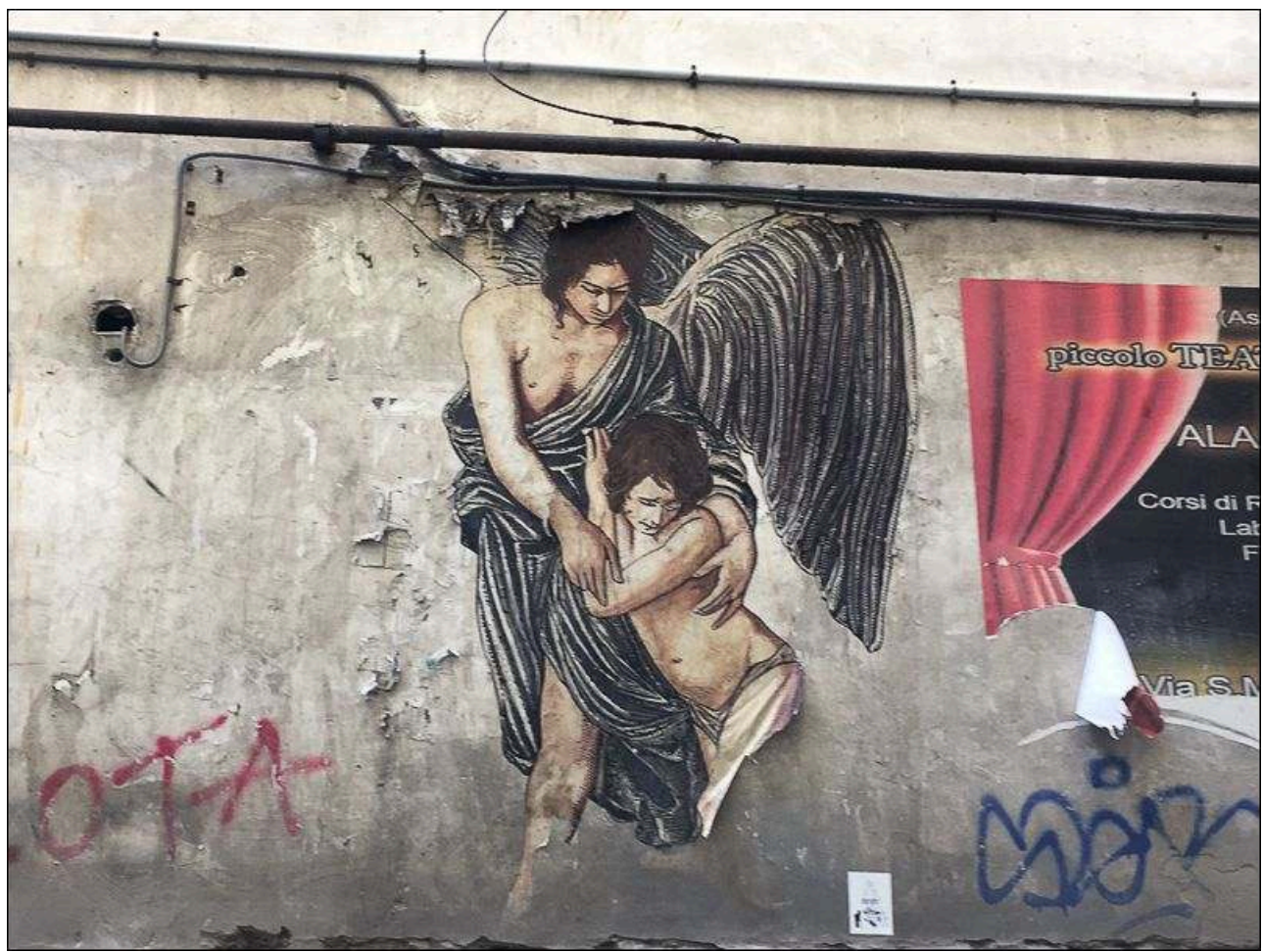

Auteur : C. Salomone, 2018

Illustration 3 - CEuvre de C215

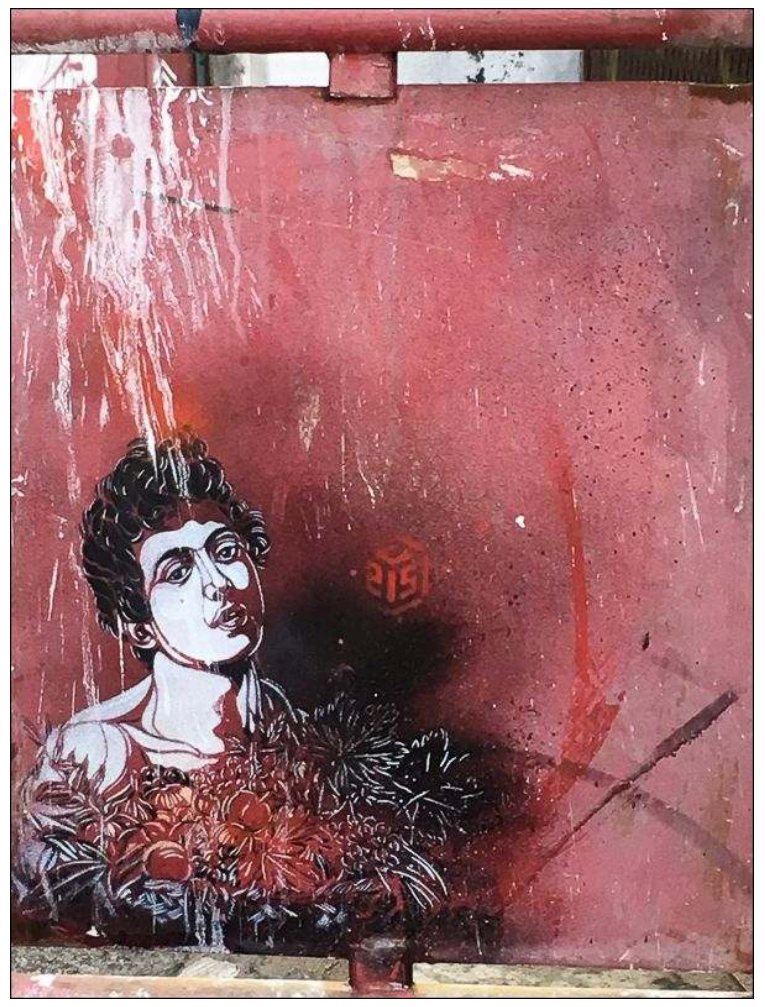

Auteur : C. Salomone, 2018. 
Illustration 4 - Euvre de Mr Chat

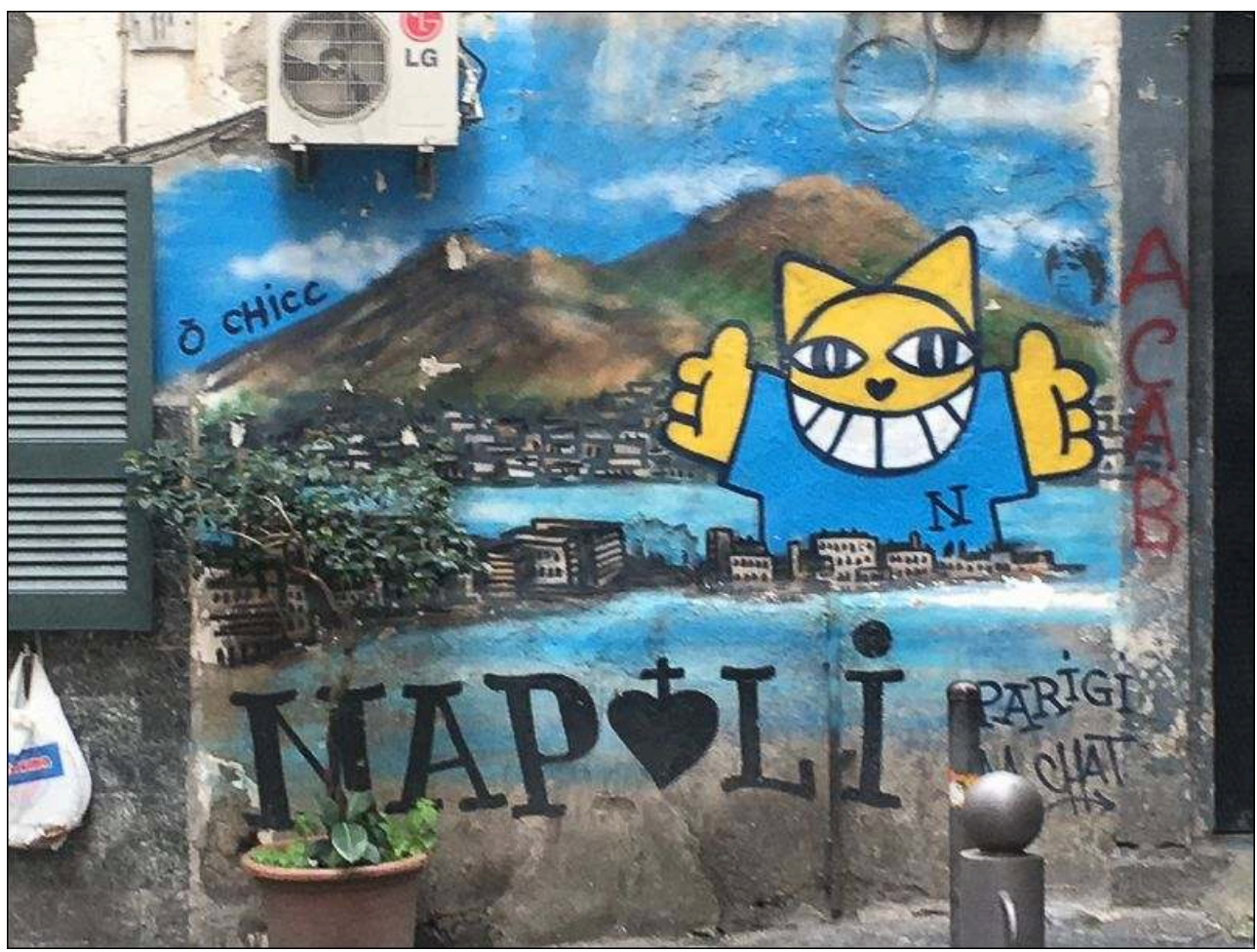

Auteur : C. Salomone, 2017

Illustration 5 - CEuvre de Bansky

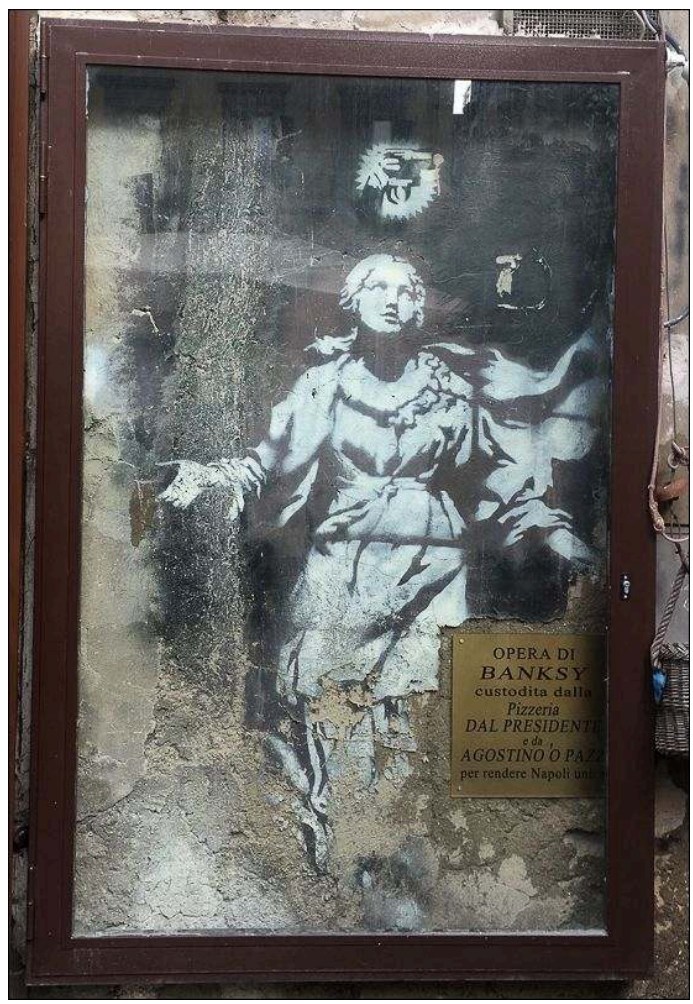

Auteur: C. Salomone, 2018 
17 Parallèlement, les initiatives des artistes locaux s'affirment dès les années 1990, notamment en lien avec les centres sociaux occupés ${ }^{15}$, lieux d'expression d'un art urbain contestataire, favorisant la production de modèles culturels alternatifs (Dines, 1999): Officina 99 (ouvert en 1991) dans le quartier de Gianturco ou le SKA (" laboratoire occupé pour une expérimentation de culture antagoniste ») créé en 1995 dans le centre historique. Les graffitis et fresques ornant sa façade symbolisent ces combats politiques et sociaux ${ }^{16}$ et marquent une forme de réappropriation spontanée de l'espace du centre antique (Rossi, 2009), une manière de combattre la morosité de la ville rationnalisée par des « marquages anomiques » (La Rocca, 2013).

Illustration 6 - Façade du SKA, laboratoire occupé dans le centre historique

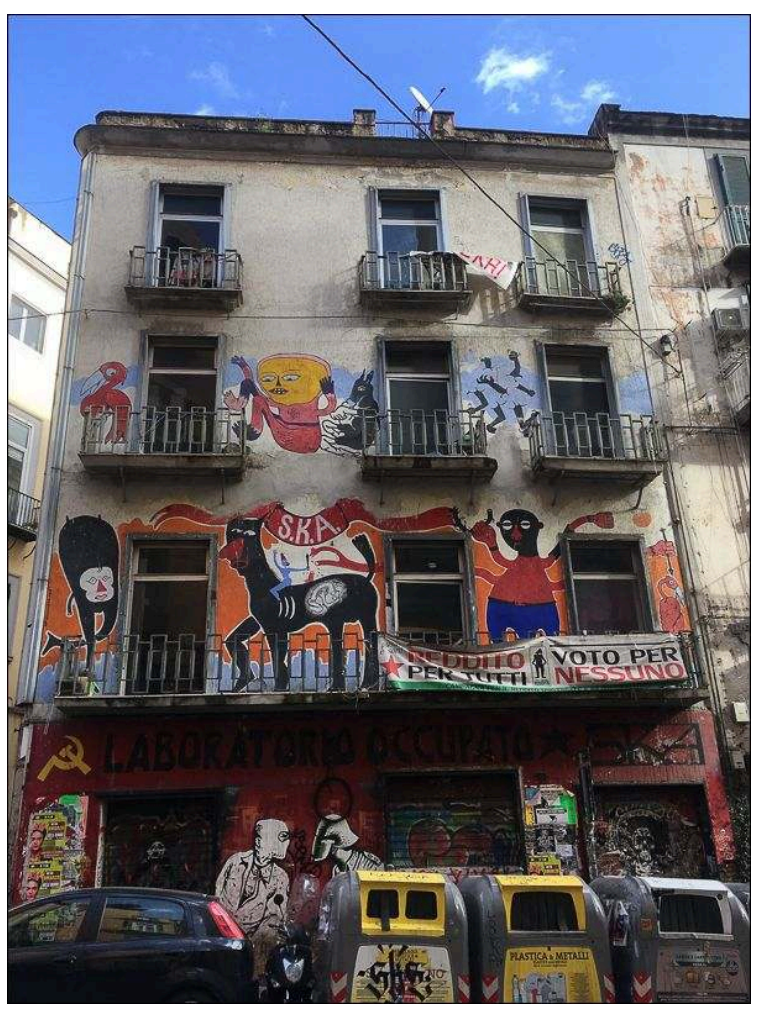

Auteur : C. Salomone, 2017.

Plus récemment, d'autres lieux de la contestation sont apparus à Naples dans le cadre $\mathrm{du}$ mouvement des biens communs, favorisant l'épanouissement de ces interventions artistiques. La ville devient le laboratoire d'expériences d'occupation illégale de lieux culturels depuis 2011 à l'image de toute l'Italie (Festa, 2016). Ces nouvelles formes de résistance urbaine interrogent les régimes de la gouvernance comme avec l'exemple de l'ex-Asilo Filangieri ou de l'ancien hôpital psychiatrique de Materdei (Froment, 2016) (illustration 7). Dans un contexte de néo-libéralisme marqué par le recul de l'État et suite aux politiques d'austérité liées à la crise de 2007-2008, ces expérimentations illustrent le rôle de la société civile et les interventions bottom up dans le champ culturel et social. Elles témoignent de la vivacité des associations et des mobilisations collectives dans le Sud de l'Italie (Ramella, 1995 ; Trigilia, 1995). Le domaine des biens culturels s'ouvre ainsi à d'autres acteurs, privés, issus du monde associatif ou simple citoyen. Les espaces urbains se transforment en enjeu de la mise en question de l'action publique en matière de culture (Froment, 2016). 


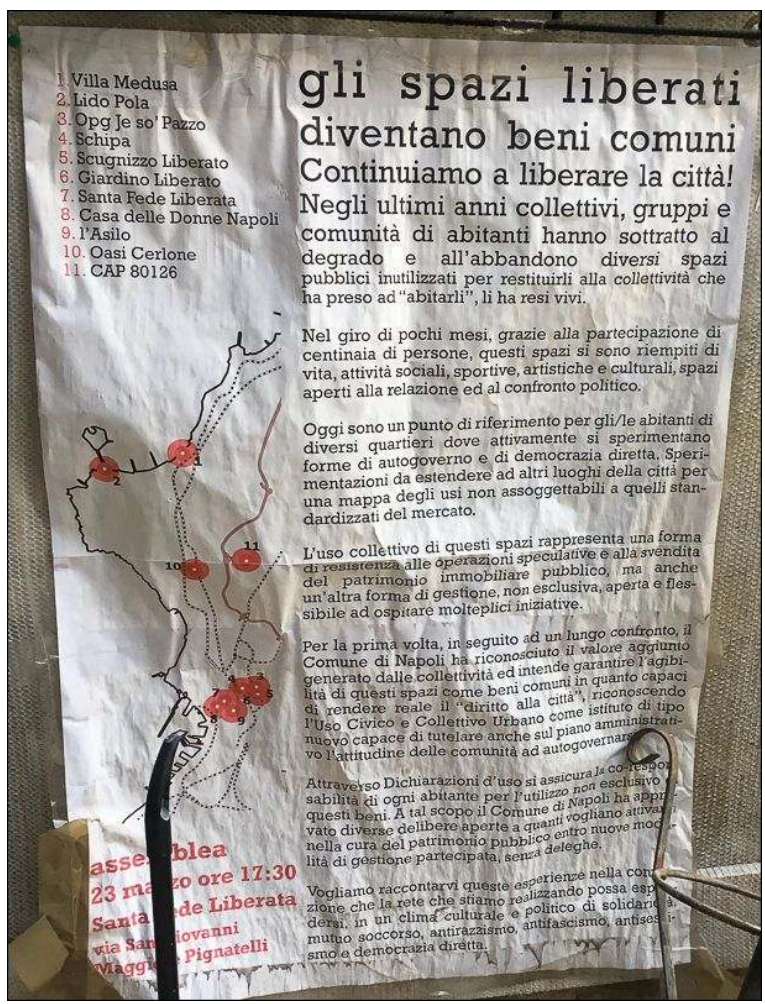

Affiche pour une assemblée populaire apposée à l'entrée du site titrée « Les espaces libérés deviennent des biens communs. Continuons à libérer la ville ».

Auteur : C. Salomone, 2018.

Ainsi, la municipalité De Magistris régularise ces expériences d'occupation de lieux abandonnés ${ }^{17}$, réinvestis par des collectifs du secteur de la culture ou du social. En 2011, elle modifie son statut communal et adopte la charte des espaces publics (2013). La reconnaissance opérée est l'indice de la mise en place de low budget et de bottom-up policies où la politique culturelle est largement dévolue à la société civile dans un contexte de rareté de l'argent public (Froment, 2015). Ces expériences d'occupation illégale se traduisent par des processus de territorialisation (Festa, 2012). Symboliquement, la réappropriation des lieux se poursuit au moyen d'actions créatives, mobilisant les street-artistes: fresques, ateliers, happenings, expositions et événementiel (Voir Illustrations 8 à 11 concernant les interventions artistiques sur les murs de l'ex-hôpital psychiatrique de Materdei). La profusion des œuvres et leur dispersion dans l'espace urbain confirment la vitalité culturelle de la ville et témoignent d'un ancrage relativement ancien de cette pratique artistique. Apparue et développée dans le sillage des centres sociaux occupés dès les années 1980-90, elle s'épanouit aujourd'hui grâce à ces artistes attachés à une veine contestataire. 
Illustration 8 - C Fuvre de Diego Miedo

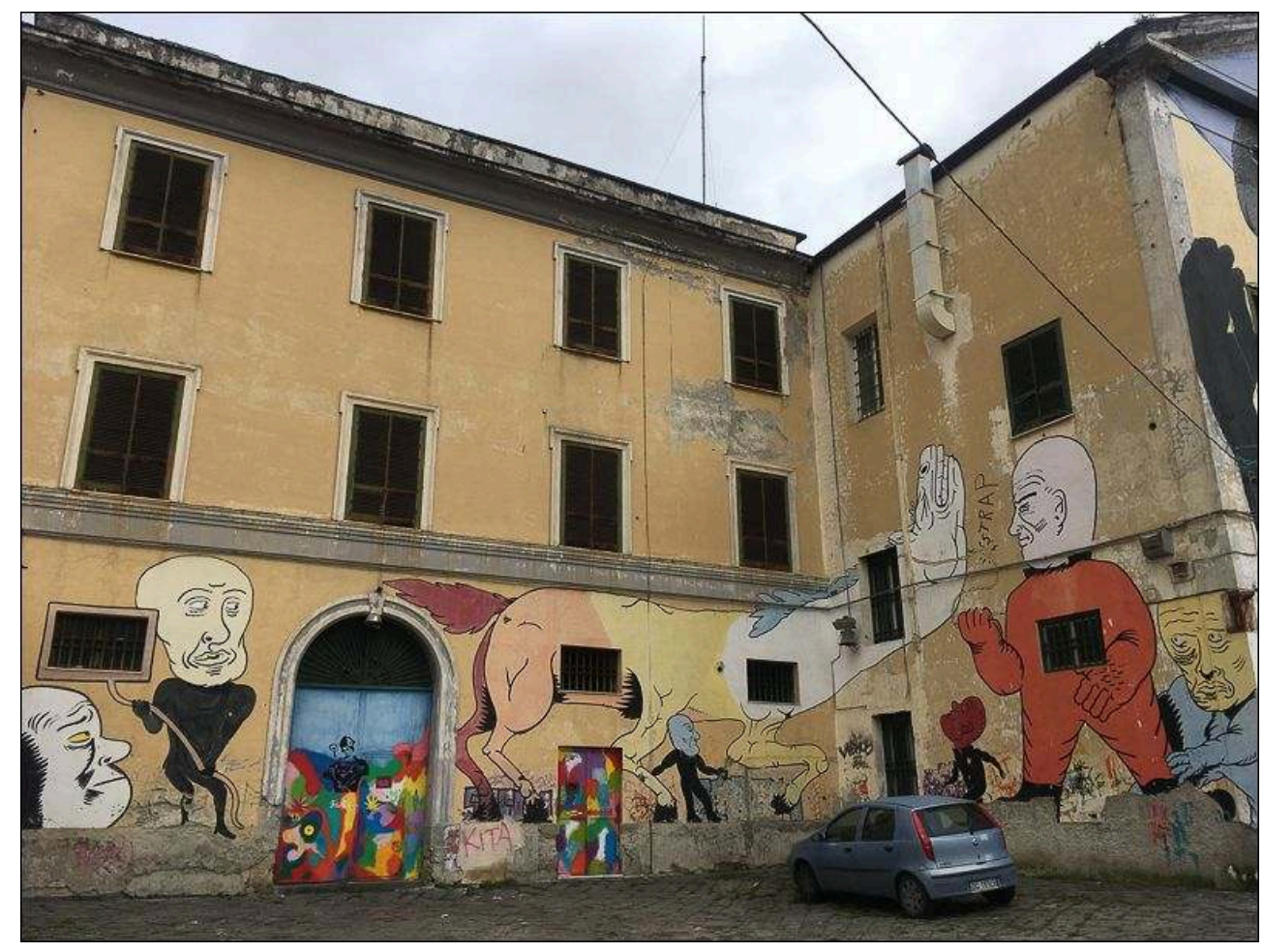

Auteur : C. Salomone, 2018.

Illustration 9 - CEuvre de Felipe Cardegna (street artiste espagnol)

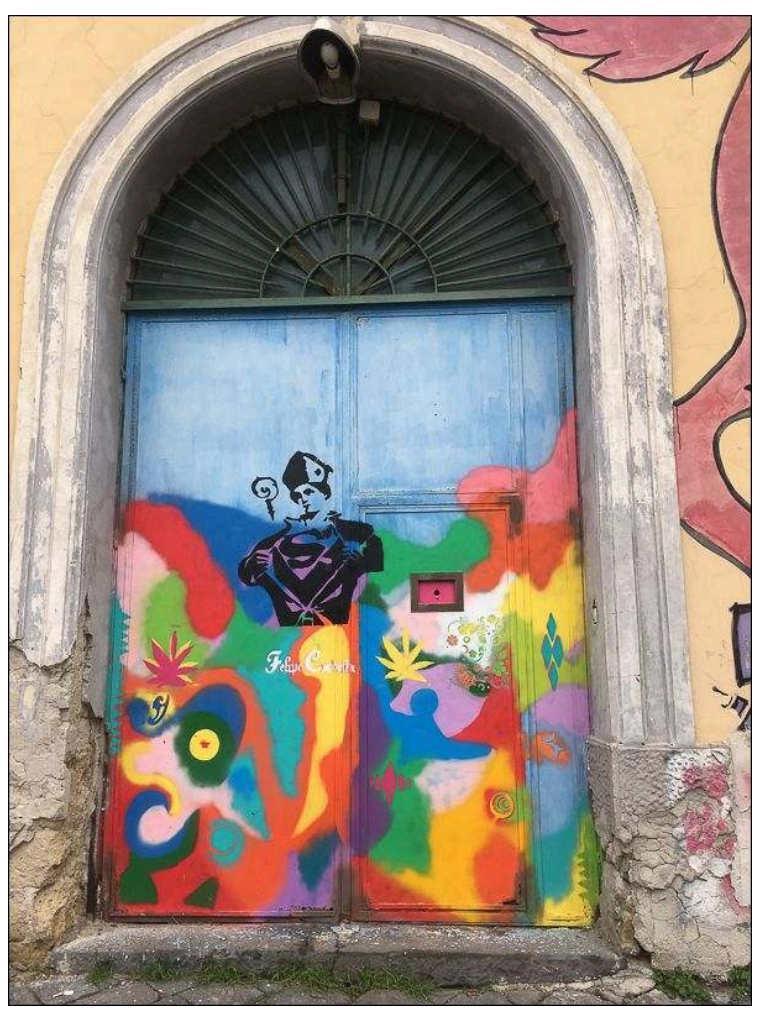

Auteur: C. Salomone, 2018. 
Illustration 10 - Euvre d'Ericailcane réalisée en novembre 2017 (artiste originaire de Vénétie)

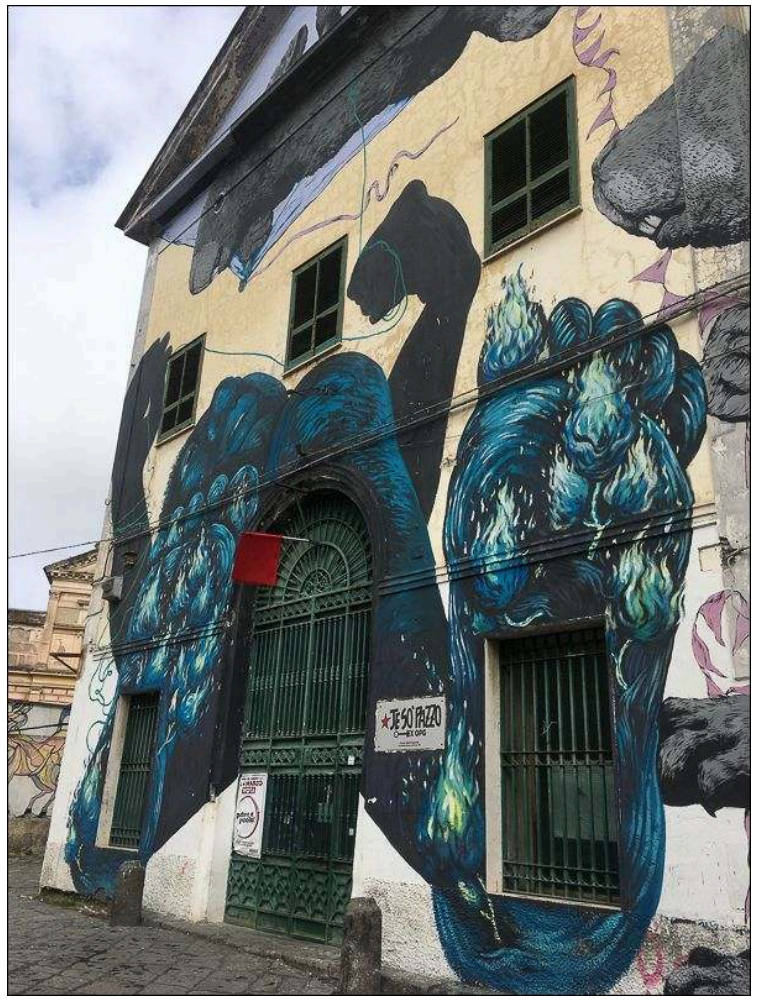

Auteur : C. Salomone, 2018

Illustration 11 - Euvre de Blu (célèbre artiste italien originaire de Bologne)

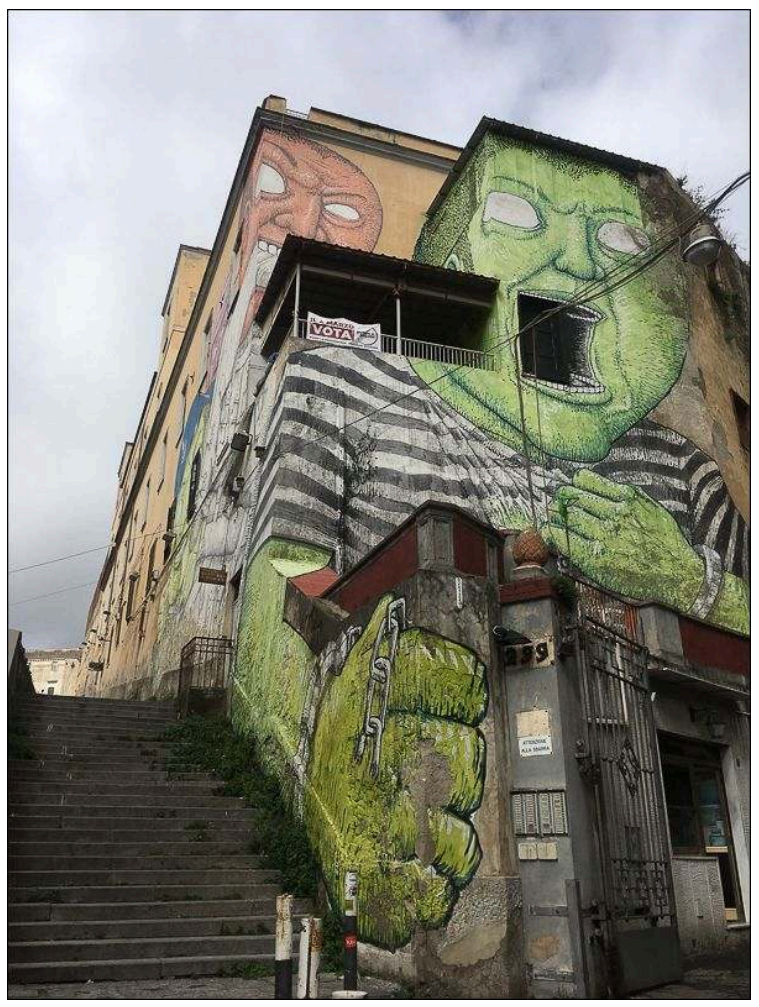

Auteur : C. Salomone, 2018 


\section{Discours de street artistes : entre pratiques protestataires et refus de l'institutionnalisation}

20 La ville se couvre ainsi des productions réalisées par ces artistes italiens et locaux dans divers quartiers, en lien avec le territoire et ses habitants. Les artistes interrogés lors des entretiens ${ }^{18}$, en dépit de la diversité de leurs origines et de leur parcours ${ }^{19}$, offrent à travers leurs discours certaines similitudes. L'expression même de street artiste est refusée car, à leurs yeux, elle "enferme l'artiste derrière une étiquette " (entretien Cyop and Kaf, février 2017), et constitue une "catégorie imposée par le haut» (entretien avec Gennaro Maria Cedrangolo, février 2018). À travers leur engagement, ils relèvent de ce street art contestataire, dans la typologie de Genin (2015), rejetant le système en place et s'inscrivent dans une démarche politique ou sociale : «C'est ça la force du street art, c'est que de manière non évidente, il te fait passer un message ; ça en revanche, c'est de la propagande » [en évoquant le muralisme de certaines œuvres de l'ex-OPG de Materdei] (entretien avec G. M. Cedrangolo, 2018). Leurs interventions spontanées conservent un caractère transgressif, comme le prouvent les tracasseries administratives auxquelles ils sont confrontés. Cette position leur garantit une grande liberté d'action et les situe en dehors du monde de l'art officiel. Toutefois, ils reconnaissent avoir modifié la nature et les conditions de leur pratique où à l'activisme d'antan ${ }^{20}$ a succédé un street art plus "soft", plus protestataire (Genin, 2015). Ils acceptent parfois d'intégrer des circuits de l'art plus classiques (expositions, galeries), sans rompre totalement avec cette culture underground.

Véritablement ancré dans le territoire où ils opèrent, le choix du quartier influence souvent leur stratégie artistique (paysage urbain, lien avec la population). Ainsi, le duo d'artistes napolitains, Cyop and Kaf, réalise entre 2009 et 2013 plus de 223 œuvres dans les Quartiers espagnols, situés en bordure du centre antique, bénéficiant dans sa partie basse des effets de la requalification du centre historique (illustrations 12 et 13). Une démarche ouverte sur l'histoire du lieu et sur le quotidien des habitants, réalisée avec leur accord voire leur collaboration, mais sans aucun lien institutionnel. À leurs yeux, il s'agit d'un véritable récit urbain et l'acte lui-même né du projet est aussi important que le résultat. Dans la même veine artistique, Diego Miedo, a multiplié ses créations dès 2006-2007 dans les ruelles du centre, mais surtout dans l'ancien quartier industriel de Gianturco, situé à l'est de Naples, un quartier « hybride » très fréquenté par les street artistes $^{21}$. Il y opère pendant plus de dix ans et ses œuvres recouvrent les friches et les murs des bâtiments abandonnés, une manière pour l'artiste d'être à l'écoute d'un territoire totalement en déshérence, un " lieu en marge », un « lieu oublié » : « Nous ne voulons pas requalifier, nous ne sommes pas des politiciens. Nous voulons être ici, languissants à vous écouter, si vous le permettez. Et en vous écoutant, vous rencontrer, en écrivant, en dessinant, se rencontrer » (Miedo et Schiavon, 2016, p. 6).

Ils se différencient des artistes en quête de notoriété ou de reconnaissance par le biais d'œuvres de commande ou acceptant une institutionnalisation. Très critiques à l'égard des actions menées par les opérateurs « institutionnalisés » comme INWARD (voir note 30), qualifié de «bureaucratie du street art $^{22}$ » par Cyop and Kaf, ils privilégient une démarche purement artistique et un engagement plus politique ou social. La mise en tourisme de leurs créations et leur valorisation s'effectuent souvent de manière fortuite. Les artistes eux-mêmes sont assez sceptiques, indifférents voire réticents : « Le 
discours sur le tourisme, cela ne m'intéresse pas » (Cyop, mars 2018). Ils refusent toute idée de s'impliquer dans une visite guidée pour en expliquer les œuvres. Leur découverte relève d'une démarche individuelle, même si certains d'entre eux agissent comme de véritables passeurs culturels. «Le street art, tu dois le découvrir tout seul (...). J'essaie d'être le moins académique possible. Eux, ils ne savent pas expliquer leur art et ils ne veulent pas qu'il soit expliqué de cette manière » (Entretien avec Gennaro Maria Cedrangolo, février 2018).

Conçues comme éphémères, les performances artistiques de Cyop and Kaf sont finalement devenues pérennes et médiatisées, via la publication d'ouvrages et la tenue d'un site internet ${ }^{23}$ avec une carte interactive localisant les œuvres. Il n'y a pas d'explication ou d'interprétation des œuvres et les auteurs semblent refuser l'idée de leur rôle dans une éventuelle requalification du quartier. Tous dénoncent cette rhétorique institutionnelle sur la prétendue requalification du territoire : un discours erroné des acteurs politiques qui instrumentalisent la démarche artistique. Le duo rejette également la démarche de la municipalité, avec la mise en œuvre du pacte des biens communs, la légalisation du street art et son choix d'autoriser les artistes sélectionnés à occuper certains espaces. Perçue comme une tentative de contrôler la création artistique, cette politique produit, à leurs yeux, un art insipide et aseptisé ayant perdu toute veine contestataire. Opposés ou réticents à toute forme d'institutionnalisation, ils privilégient une démarche subversive. Leurs œuvres alimentent néanmoins les circuits du street art et participent à l'émergence d'une offre touristique renouvelée.

\section{Illustration 12 - Euvre de Cyop \& Kaf dans les Quartiers espagnols de Naples}

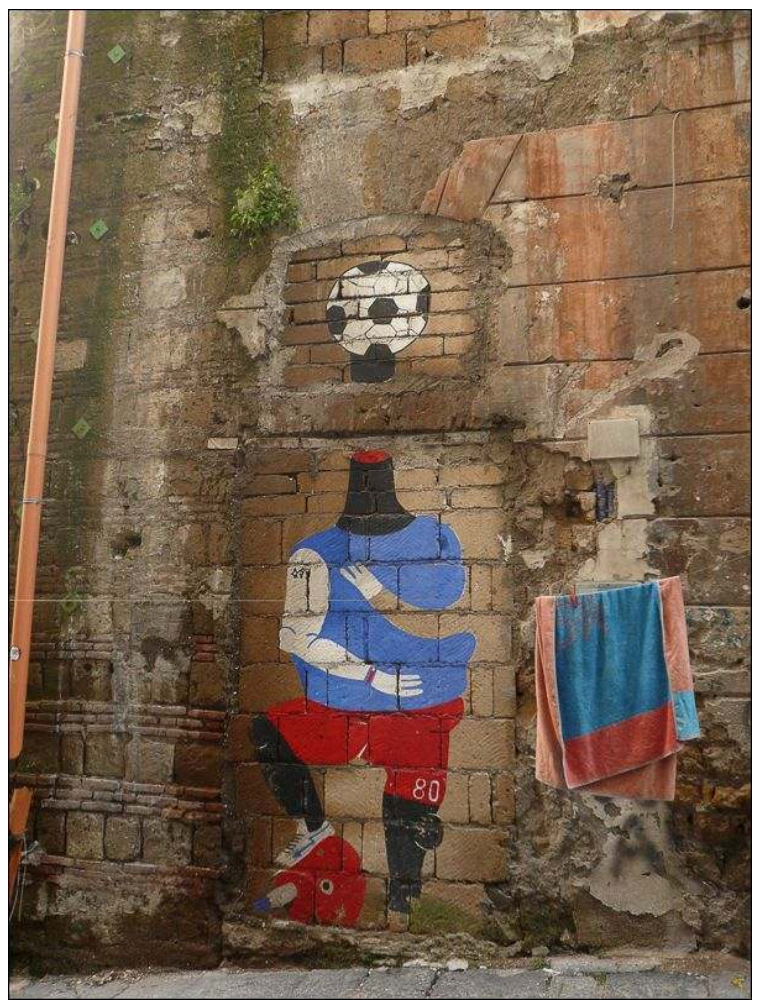

Auteur: C. Salomone, 2017 
Illustration 13 - Euvre de Cyop \& Kaf dans les Quartiers espagnols de Naples

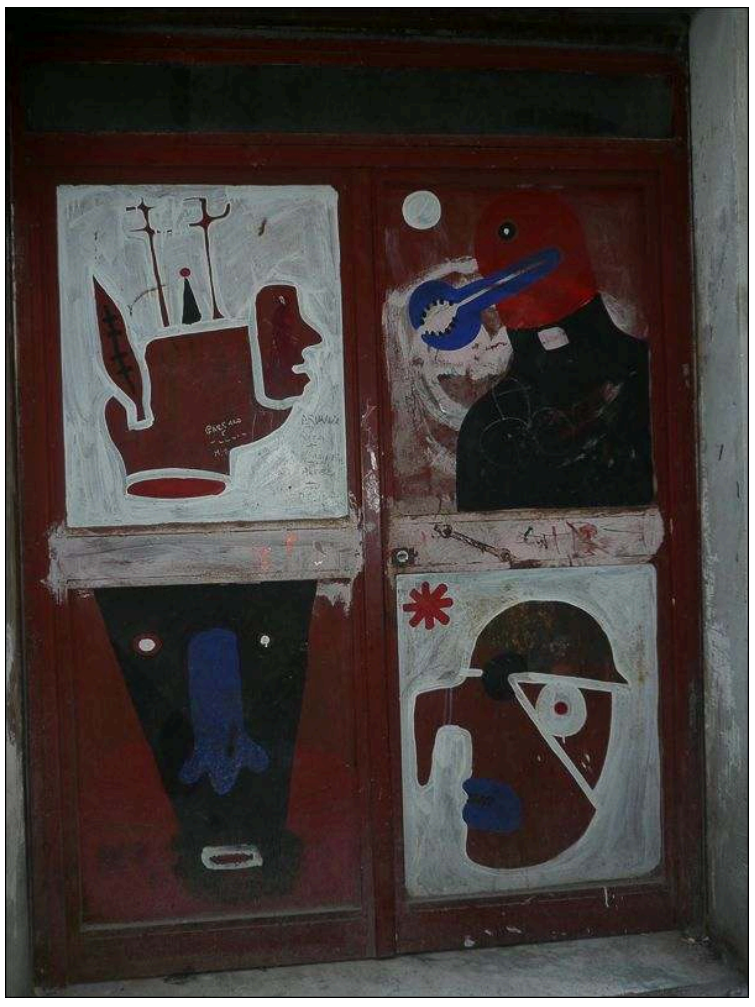

Auteur: C. Salomone, 2017.

Illustration 14 - Euvre de Diego Miedo dans le centre historique

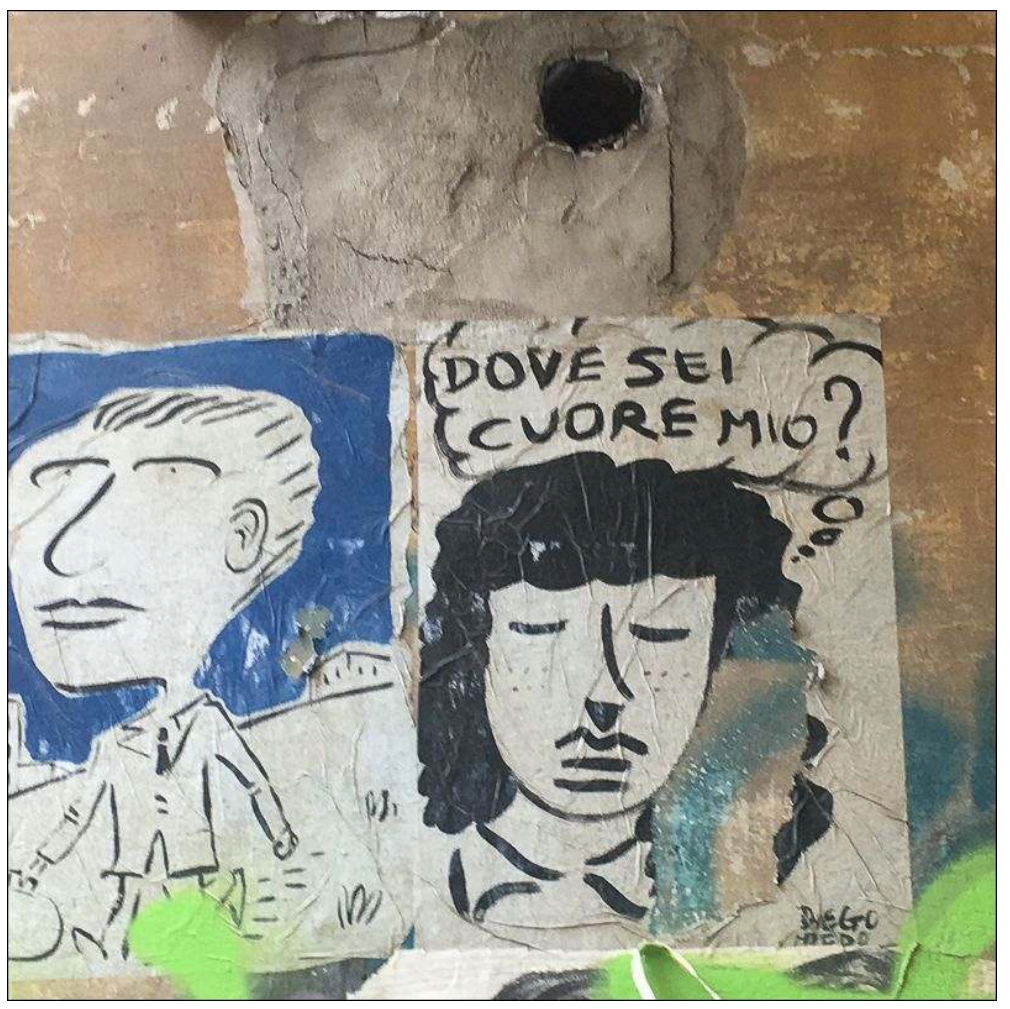

Auteur : C. Salomone, 2017. 
Illustration 15 - Affiche de promotion d'un circuit « Murals Tour » de Diego Miedo

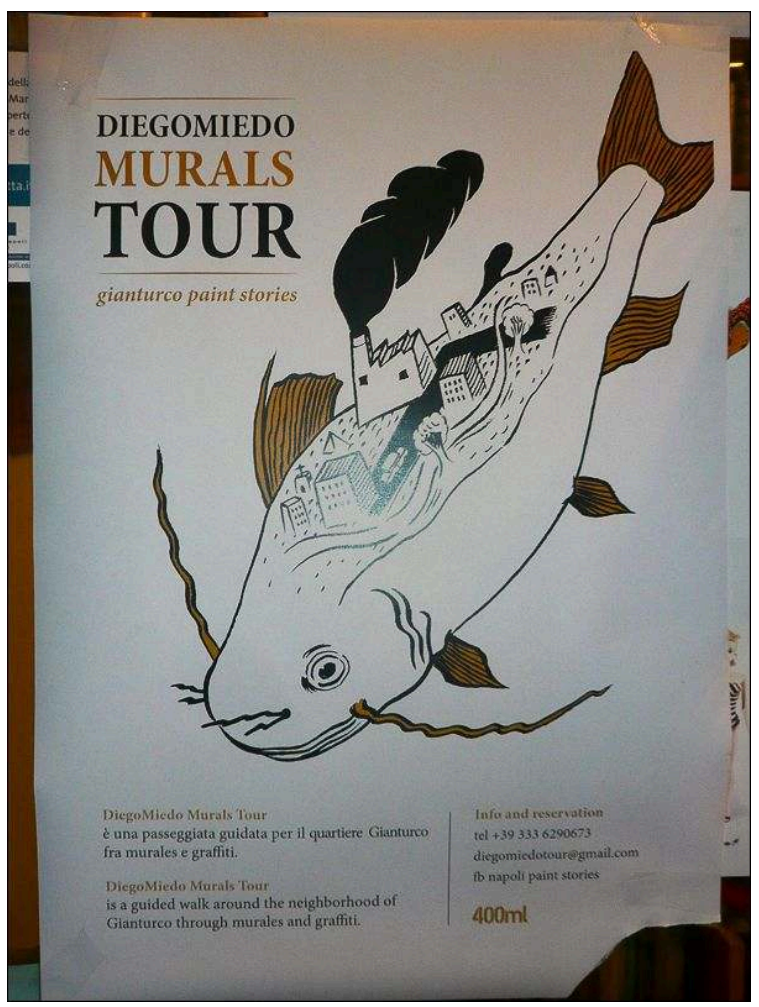

Affiche exposée dans une librairie du centre historique. Auteur : C. Salomone, 2017. 
Illustration 16 - CEuvre de Diego Miedo sur les murs d'une école

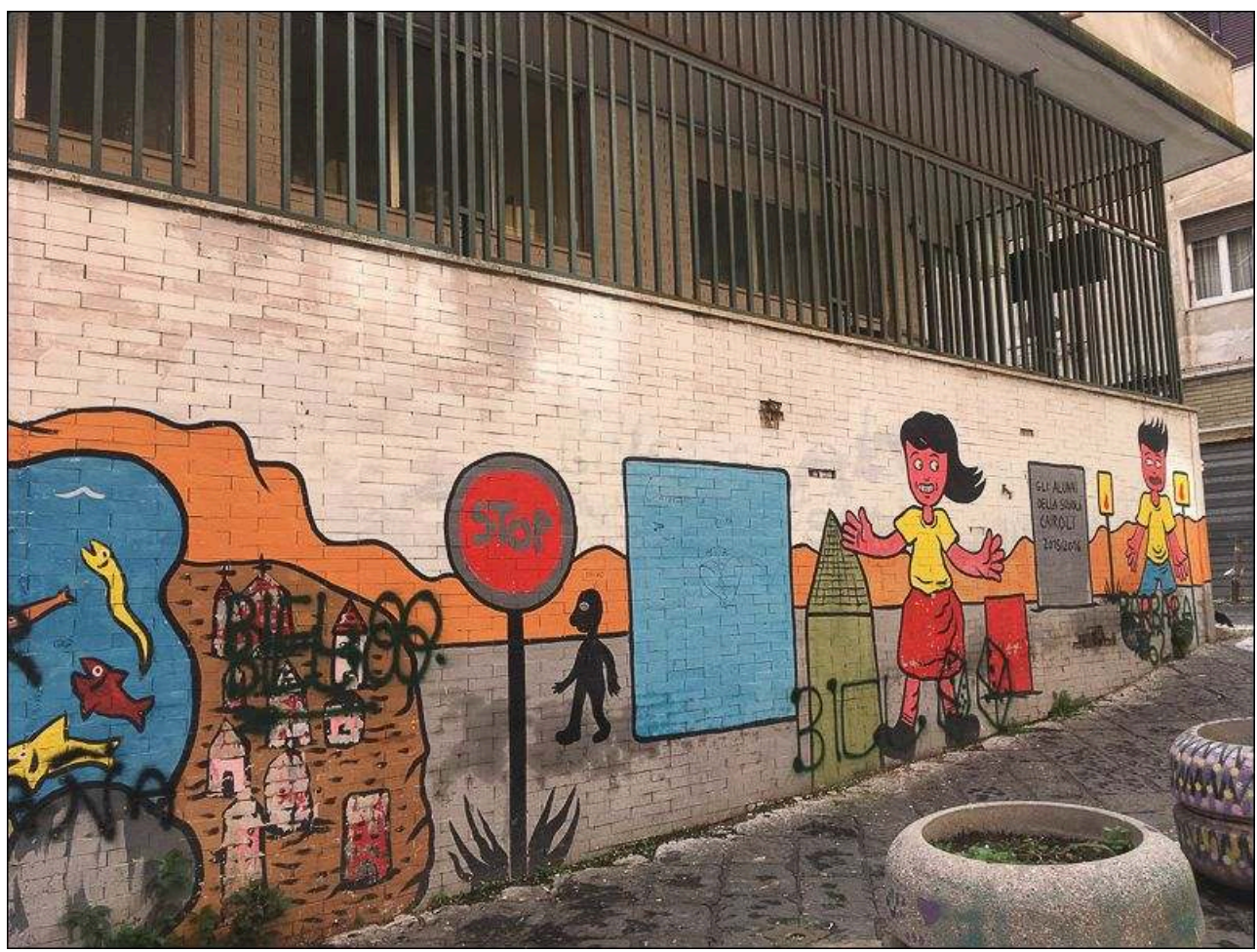

Auteur : C. Salomone, 2017

\section{L'émergence d'une offre touristique éclatée et disparate}

Rarement ces expérimentations artistiques menées dans les quartiers abandonnés ou marginaux, avec le concours plus ou moins appuyé des habitants, font l'objet d'une mise en tourisme officielle. Toutefois, des initiatives spontanées de découverte de l'espace urbain sont organisées, avec la mise en place de circuits. Parfois, les habitants s'improvisent médiateurs du projet artistique ${ }^{24}$ avec le soutien des artistes ou encore le relais s'effectue par le biais d'associations culturelles engagées. La rencontre de Napoli Paint Stories, association créée par une jeune étudiante ${ }^{25}$ en conservation des biens culturels, passionnée de street art, avec l'association $400 \mathrm{ml}$, composée de jeunes créatifs urbains, donne naissance à un premier parcours de découverte en décembre 2014 qui se maintient depuis de manière irrégulière et privilégie le centre historique. 
Illustration 17 - Carte du circuit street art de l'association Napoli Paint Stories dans le centre historique

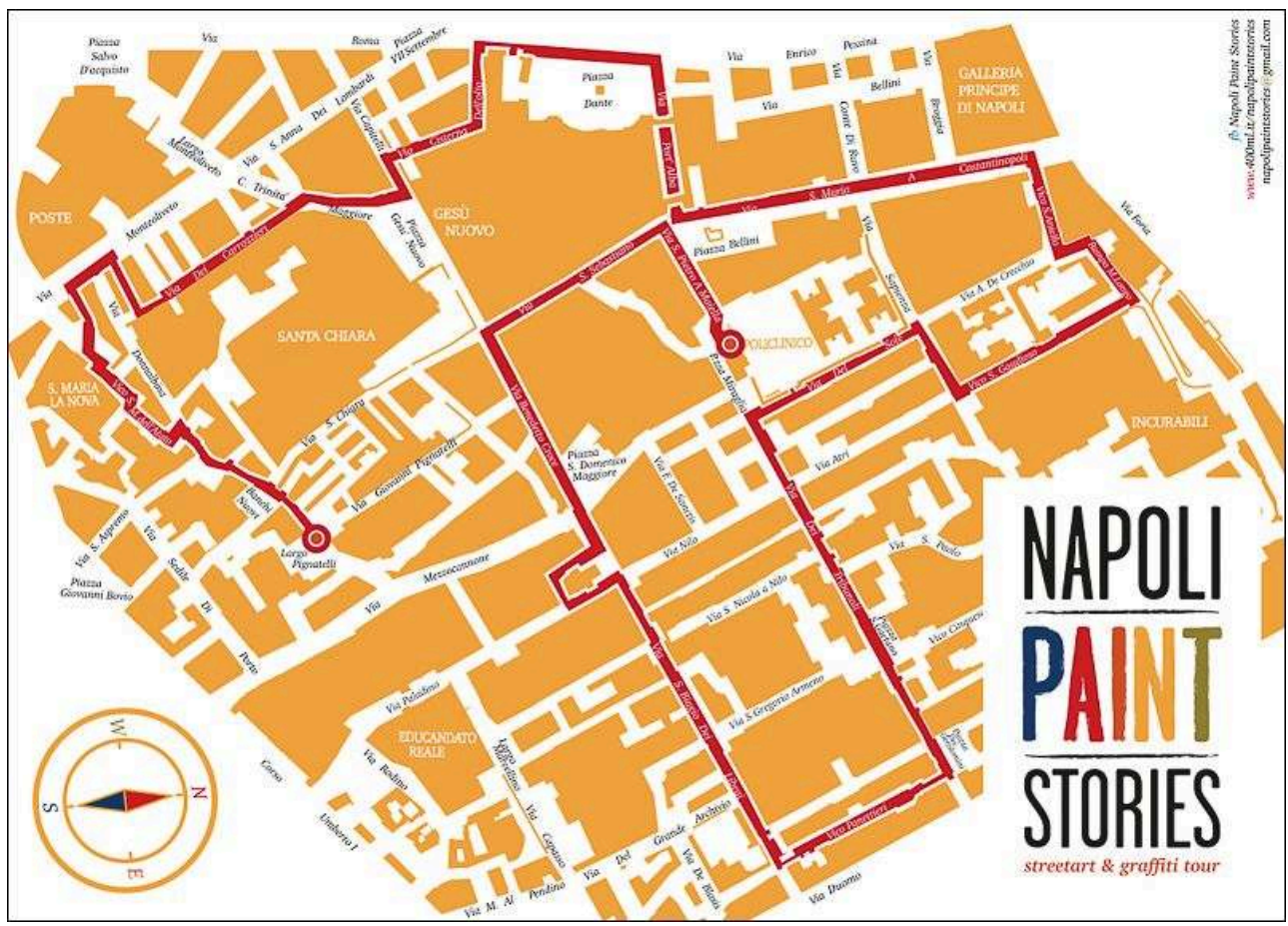

Source : Napoli Paint Stories.

Ce projet bénéficie initialement de financements publics ${ }^{26}$ dans le cadre d'une politique municipale en faveur de la jeunesse et de la créativité dans les quartiers fragilisés ${ }^{27}$. Pour la municipalité, il s'agit à la fois de favoriser une expérience éducative en visant un public jeune et de combattre les tags par la connaissance de l'art urbain. Parallèlement, d'autres opérateurs touristiques napolitains investissent ce champ de l'art urbain en profitant de sa notoriété grandissante. Ils s'inscrivent pleinement dans ce créneau du tourisme créatif et expérientiel par la nature de leur offre et le recours aux réseaux sociaux (réservation, communication, interactivité avec le touriste). L'argument du street art n'est pas central, tout au plus permet-il de s'inscrire dans une démarche originale. Leurs propositions alternatives de découverte de l'espace, s'adressent à de petits groupes de "voyageurs " pour un tourisme sur mesure ${ }^{28}$ (Vascitour). Ces visites guidées s'appuient sur la présence d'un accompagnateur local, un «local friend» (Vascitour, Tour Angels), gage d'une rencontre présentée comme véritable et d'une "authenticité " présumée. Les circuits se concentrent dans les quartiers les plus accessibles et à forte densité patrimoniale. Par leur offre originale et différenciée, ces acteurs tentent de satisfaire les attentes d'une clientèle en quête de renouveau et créativité. Le street art enrichit ainsi l'offre touristique napolitaine. Il alimente ce créneau du tourisme créatif, en dépit d'une faible promotion et de la dispersion des œuvres. Les interventions artistiques récentes menées à la Sanità et à Ponticelli pourraient alors renforcer cette mise en tourisme et sa valorisation. 


\section{Le street art au service de la requalification d'un quartier?}

En effet, les quartiers napolitains de la Sanità et Ponticelli ont vu fleurir très récemment des œuvres de street art, utilisées comme support à des projets de requalification. Quoique très différents, ils apparaissent socialement et économiquement fragilisés et souffrent d'une mauvaise réputation. L'aire VerginiSanità ${ }^{29}$, située au nord du centre antique, est une marge du centre historique. Inscrit dans le périmètre du Patrimoine mondial de l'humanité, ce quartier populaire et industrieux est un espace enclavé ; son riche patrimoine a fait l'objet d'une valorisation par un tissu d'acteurs associatifs très dynamiques (Salomone, 2013, 2015). À l'inverse le quartier Ponticelli, situé à l'est de Naples (à $4 \mathrm{~km}$ de la gare centrale), est un quartier périphérique frappé par le chômage et des taux élevés de criminalité. Périphérie populaire, marquée par une intense spéculation immobilière et l'importance des logements sociaux, cette aire affronte depuis les années 1970 une longue période de désindustrialisation.

\section{Au cœur d'un projet de régénération sociale : le «Parc des Murales » à Ponticelli}

Dans ce quartier fragilisé, la créativité et l'art urbain sont mobilisés par des acteurs associatifs comme instruments au service de la régénération sociale et de la requalification urbaine. Le projet est porté par l'observatoire de la créativité urbaine, INWARD (International Network on writing art Research and development) ${ }^{30}$. Cet observatoire napolitain, fondé en 2006 par l'association culturelle Arteca, est engagé dans la valorisation du street art à Naples et en Italie ${ }^{31}$. Dès 2008, il collabore avec les acteurs institutionnels locaux et nationaux pour mettre en œuvre un modèle de valorisation du street art (Entretien avec Luca Borriello, février 2018) (illustrations 18-19). Acteur associatif « institutionnalisé », il est engagé dans la professionnalisation de cet art urbain et sa reconnaissance. 
Illustration 18 - Euvre de Jorit, San Gennaro (Decumani)

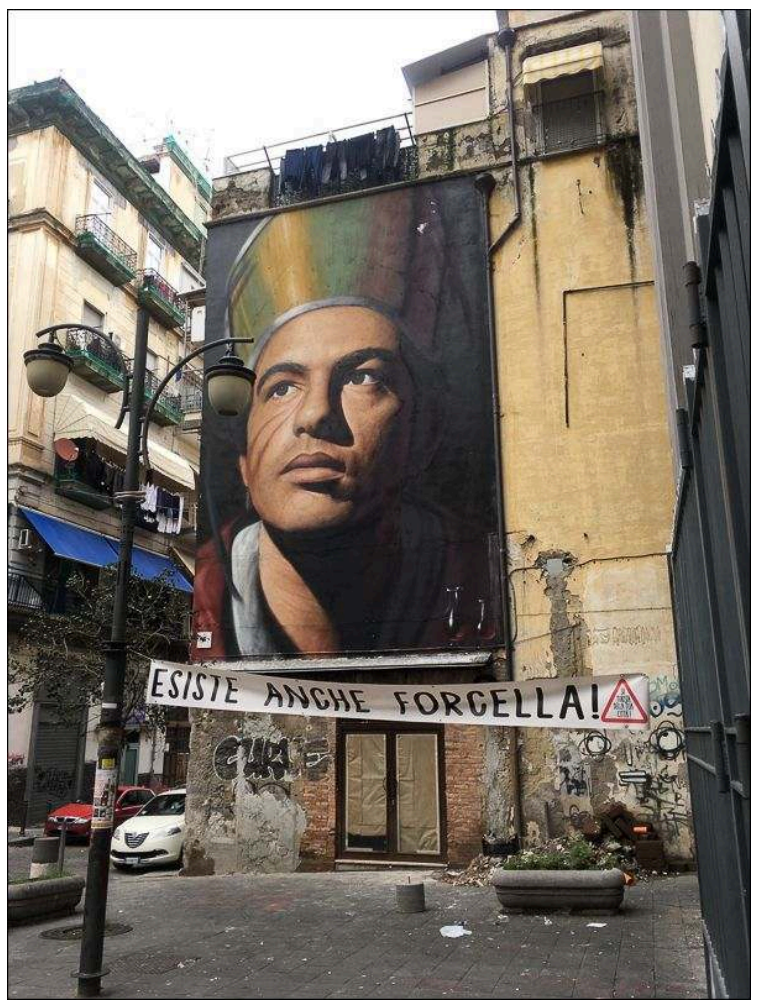

Auteur : C. Salomone, 2017

Illustration 19 - Fresque sur une station de la Circumvesuviana

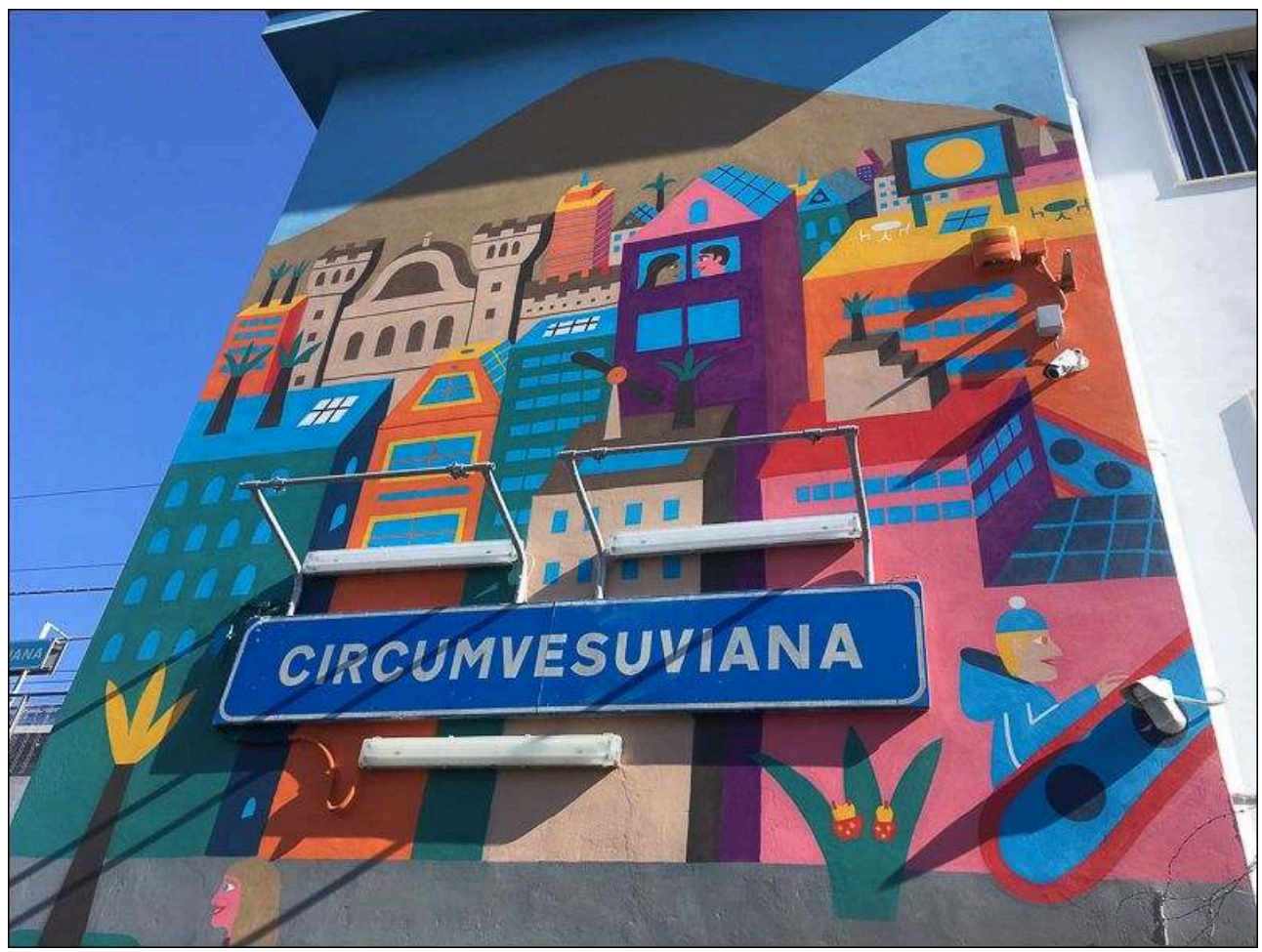

Fresque financée par Inward et un partenariat avec une entreprise privée.

Auteur : C. Salomone, 2018. 
En 2015, INWARD lance l'initiative du «Parc des Murales » : huit fresques sont prévues dans le parc Merola, un ensemble paupérisé de logements - où vivent 160 familles édifié suite au tremblement de terre de 1980. À travers la participation des habitants et l'implication des artistes, le projet ambitionne de raconter les valeurs de la communauté par l'art urbain et de recréer du lien social. La démarche obéit à une visée sociale et pédagogique en faveur d'un «vivre ensemble» (Milliot, 2000) (illustration 20). Il est présenté par ses protagonistes comme un projet de « requalification artistique et de régénération sociale » où l'attention est portée à la fois sur le choix des artistes ${ }^{32}$, le dialogue avec le territoire et le projet social.

Illustration 20 - Fresque de Jorit dans le Parc des Murales

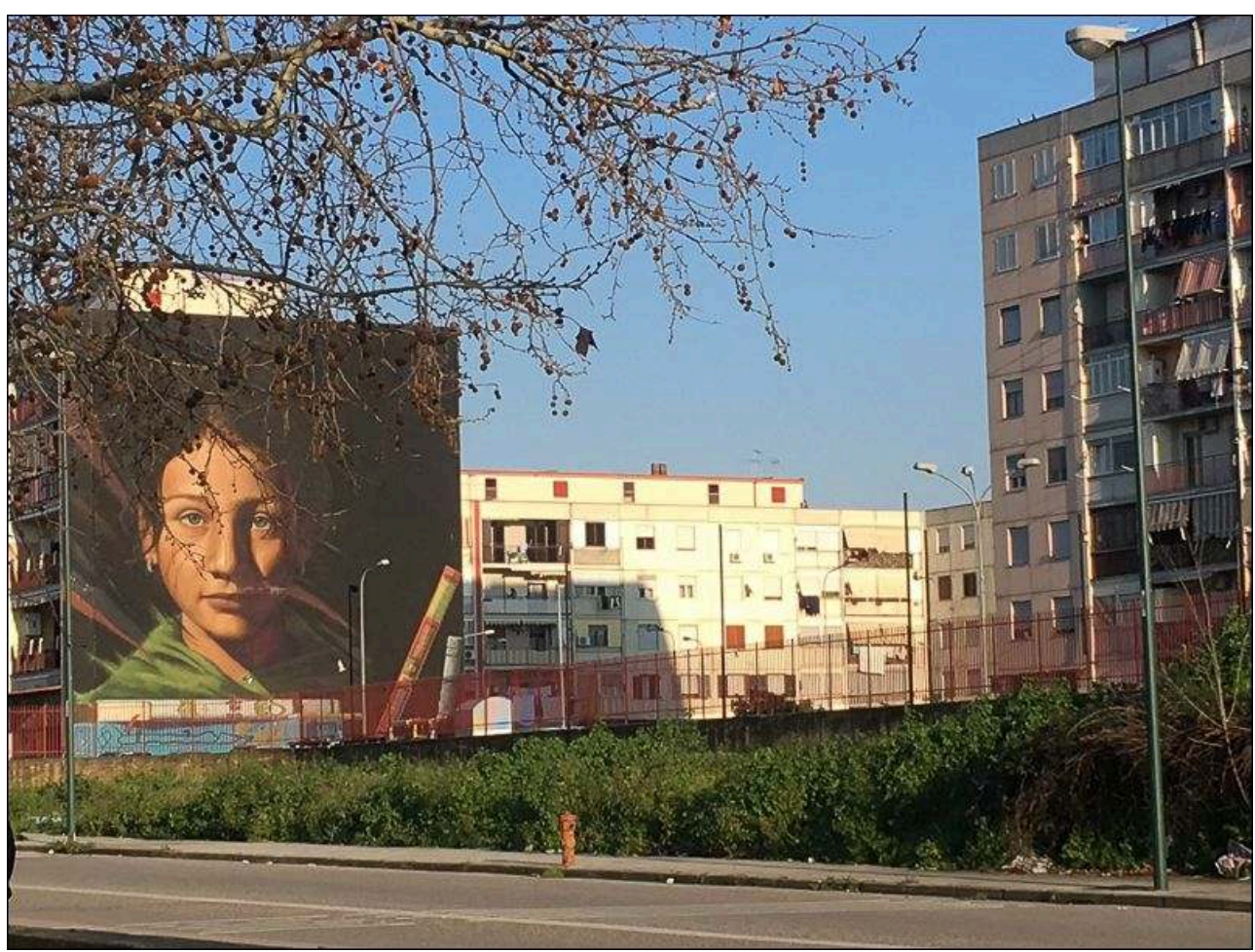

L'œuvre de Jorit intitulée en napolitain Ael. Tutt'égual song'e criature est inspirée d'une jeune fille rom rencontrée par l'artiste dans un camp à Ponticelli. II rappelle ainsi l'épisode douloureux de l'incendie d'un camp rom à Ponticelli.

Auteur : C. Salomone, 2018.

Décrit comme le premier district du street art à Naples, l'expérience fait naître un tourisme alternatif dans cette périphérie excentrée (illustration 21) grâce à l'organisation de visites guidées menées par une coopérative locale (Arginalia) favorisant une ouverture du quartier sur l'extérieur. La collaboration nouée avec l'association Econote ${ }^{33}$ (petite association environnementaliste) attire un nombre modeste de visiteurs italiens et locaux motivés par la démarche artistique. Malgré le soutien de la commune, le «produit touristique » est encore peu relayé par les acteurs locaux du tourisme ${ }^{34}$ ou dans les guides.

Illustration 21 - Divers circuits de visite organisés au Parc des Murales

Modalités de la visite et opérateur
Public 


\begin{tabular}{|c|c|}
\hline Des tours organisés avec l'association ECONOTE & $\begin{array}{l}\text { Une cinquantaine de participants (11 avril 2016, } \\
11 \text { juin 2016) }\end{array}$ \\
\hline Un street art tour créatif & $\begin{array}{l}\text { Participation de l'artiste d'origine indienne I. } \\
\text { Sathba ( } 25 \text { juillet 2016) }\end{array}$ \\
\hline $\begin{array}{l}\text { Un street art tour avec la participation d'étudiants } \\
\text { et de chercheurs }\end{array}$ & $\begin{array}{l}30 \text { jeunes en provenance de pays européens } \\
\text { (Projet Erasmus) ( } 7 \text { mai 2016) }\end{array}$ \\
\hline $\begin{array}{l}\text { Un street art tour de formation (pris en charge par } \\
\text { des jeunes dans le cadre d'un laboratoire extra- } \\
\text { scolaire « Ponticelli street art tour»). }\end{array}$ & $\begin{array}{l}\text { Participation des étudiants de l'institut } \\
\text { «Archimède » de Naples (16 juin 2016) }\end{array}$ \\
\hline Tour organisé pour les étudiants napolitains & $\begin{array}{l}\text { Étudiants napolitains de l'Université (cours } \\
\text { d'anthropologie urbaine, } 28 \text { mars 2017) }\end{array}$ \\
\hline $\begin{array}{l}\text { Tour dédié à la connaissance des réalités } \\
\text { territoriales du Tiers secteur }\end{array}$ & $\begin{array}{l}\text { Étudiants du lycée de Naples Genovesi (20 avril } \\
\text { 2018) }\end{array}$ \\
\hline $\begin{array}{l}\text { Tours organisés avec le soutien du MIBACT et du } \\
\text { SIAE : "Social tours »- projet "Sillumina » } \\
\text { (gratuité des visites guidées) }\end{array}$ & $\begin{array}{l}\text { - Premier social tour durant la réalisation de } \\
\text { l'œuvre de Daniele Hope Nitti ( } 28 \text { octobre 2017) } \\
\text { - } 60 \text { étudiants du département d'architecture } \\
\text { de l'Université de Naples (19 novembre 2017) } \\
\text { - } 50 \text { visiteurs ( } 25 \text { novembre } 2017 \text { ) } \\
\text { - Visiteurs du projet intégration et accueil pour } \\
\text { les réfugiés ( } 27 \text { novembre } 2017) \\
\text { - } 5^{\text {ème }} \text { social Tour (18 décembre } 2017 \text { ) }\end{array}$ \\
\hline Tours dédiés à des associations du territoire & $\begin{array}{l}\text { - Visite et circuit avec l'association Malfermi } \\
\text { (12 septembre 2016) } \\
\text { - Tour organisé pour l'association Igers Napoli } \\
\text { (lutte contre l'exclusion sociale) pour } \\
\text { promouvoir le territoire oriental (16 mai 2017) }\end{array}$ \\
\hline
\end{tabular}

\section{Source : données INWARD.}

Si les observateurs extérieurs y décèlent un "véritable projet de régénération urbaine ", les effets sur la requalification du bâti ou de l'environnement urbain sont toutefois peu perceptibles et l'impact sur le développement social du quartier réduit. En diffusant néanmoins un nouveau regard sur ce quartier périphérique et en rompant son isolement, cette expérimentation sociale sert aussi les ambitions d'INWARD et renforce son discours auprès des acteurs et de ses partenaires. L'importance des financements mobilisés, la forte médiatisation de cette expérimentation artistique et sociale témoignent des enjeux politiques liés à ces interventions en matière d'image et du rôle assigné à ces quartiers périphériques.

\section{Street art et renouvellement urbain à la Sanità ?}

Dans l'aire Vergini-Sanità, la dynamique autour du street art accompagne un mouvement de patrimonialisation porté par des acteurs locaux (Salomone, 2016). Une 
coopérative de jeunes issus du quartier, créée en 2006 (La Paranza), encouragée par le prêtre de la paroisse, a su y faire naître une dynamique nouvelle autour de la requalification du patrimoine et de sa valorisation touristique ${ }^{35}$. La Fondation de Communauté instituée en décembre 2014 pour fédérer les divers acteurs du territoire tente d'impulser un changement par le bas. Elle désire recréer du lien social dans ce quartier fragilisé à travers la valorisation du patrimoine et son animation et l'organisation d'événements culturels et festifs récurrents : «Créer de la communauté, que les gens reviennent dans la rue, qu'ils éprouvent ce sentiment d'appartenance, cette fierté d'habiter dans ce quartier, (...) d'en être orgueilleux» (Entretien avec M. Cappella, vice-président de la Fondation de communauté San Gennaro, 21 juillet 2016).

L'événementiel est ainsi une manière de se démarquer et de se rendre visible, tout comme les interventions artistiques dont la fonction esthétisante est souvent affirmée par ses promoteurs. À partir de 2016, les murs de la Sanità se couvrent de fresques grâce à la rencontre entre Giuseppina Ottieri de l'association « Fazoletto di perle » et le directeur des catacombes, le prêtre de la paroisse (A. Loffredo).

Illustration 22 - Diffuser un nouveau regard sur le quartier

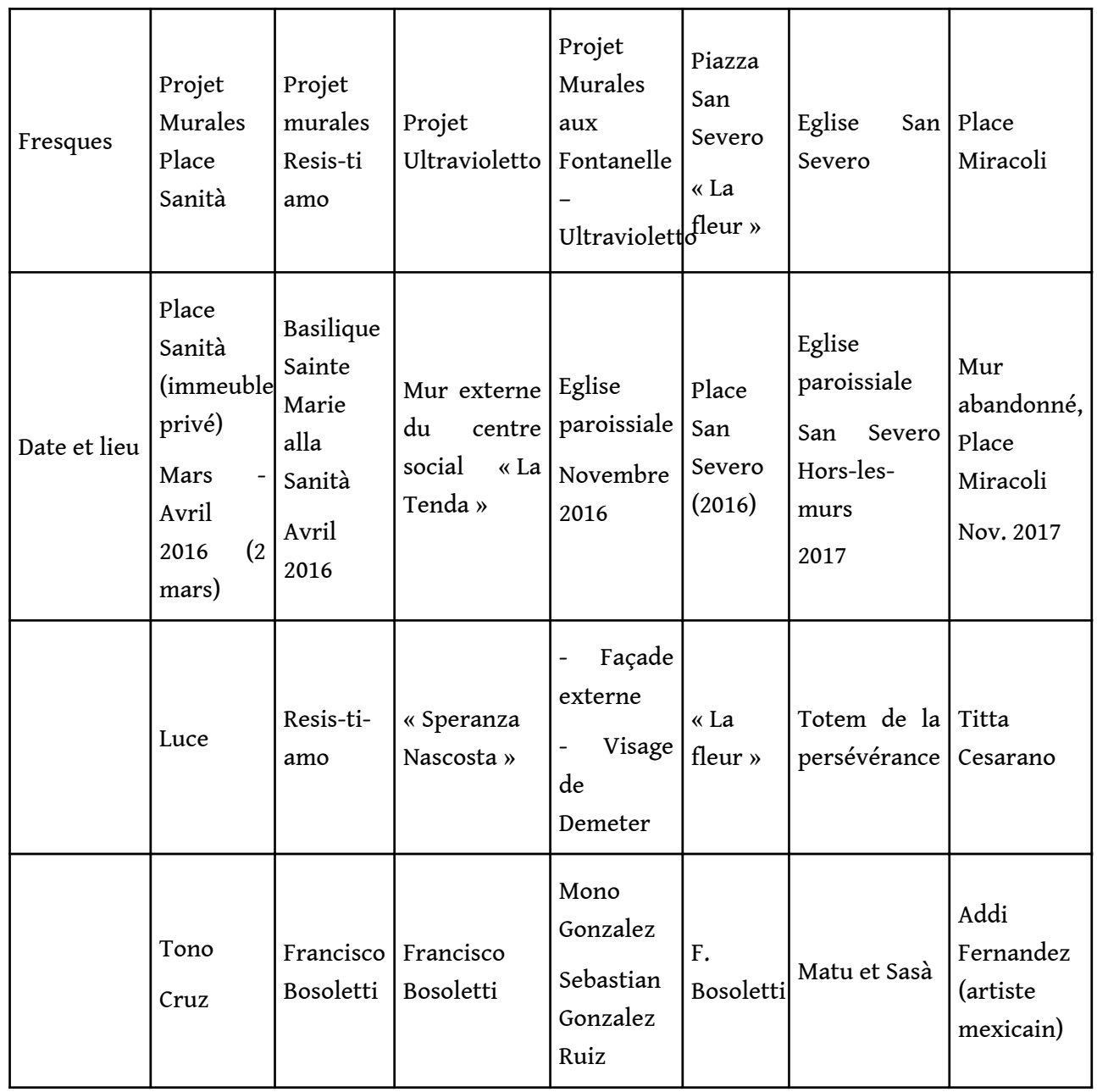




\begin{tabular}{|l|l|l|}
\hline Acteurs & $\begin{array}{l}\text { - Soutien de la Fondation de Communauté San Gennaro } \\
\text { - Soutien moral de la Commune et de l'Assessorat à l'Urbanisme } \\
\text { - Demande d'autorisation à la Surintendance Archéologie, beaux Arts } \\
\text { et Paysages (œuvres réalisées sur les édifices religieux) }\end{array}$ & \\
\hline Opérateurs & $\begin{array}{l}\text { Association « Fazoletto di perle » (association née en 2009 sans but lucratif } \\
\text { dirigée par Giuseppina Ottieri). Interlocuteur des artistes. }\end{array}$ & $\begin{array}{l}\text { Don de } \\
\text { l'artiste }\end{array}$ \\
\hline $\begin{array}{l}\text { Implication } \\
\text { des } \\
\text { habitants }\end{array}$ & $\begin{array}{l}\text { Organisation d'ateliers avec les artistes et les enfants/ habitants du } \\
\text { quartier (Luce, Projet de l'église des Fontanelle; projet «la fleur »). }\end{array}$ & \\
\hline
\end{tabular}

Sources diverses. Réalisation : C. Salomone. nouvelle représentation du lieu et créent un rapport différent des individus avec leur espace quotidien. De 2016 à 2017, sept créations artistiques couvrent certains édifices de l'aire Vergini-Sanità. L'objectif est de contribuer à changer l'image du quartier à l'extérieur et auprès de ses habitants. Présentées comme une expérience d'art participatif, les performances se réalisent avec la collaboration et l'implication des habitants, notamment des enfants du quartier. Cela contribue à leur donner une légitimité et à les faire accepter auprès de la population ${ }^{36}$ (Entretien avec G. Ottieri, 16 février 2017). Ce projet porté par les acteurs du territoire, est présenté comme un instrument de renouvellement urbain. Il bénéficie d'un large soutien de la part de la III ${ }^{\mathrm{e}}$ municipalité ${ }^{37}$ et également de la commune engagée dans le processus d'adoption des espaces publics. Il témoigne d'une nouvelle attention portée aux espaces publics et s'accompagne d'aménagements plus durables. «On va mettre en place des actions de requalification urbaine. On est déjà intervenu avec les murales, avec les projets Luce, Ultravioletto. Cela sert véritablement à cela ; c'est-à-dire à prendre soin ; le « beau » sur le plan esthétique. La requalification urbaine devient fondamentale et en accord avec ce principe, on va donc intervenir pour sauvegarder (recuperare) certaines zones du rione Sanità, notamment deux places ». (Entretien avec Enzo Porzio, membre de la Paranza, le 20 février 2017).

La valorisation du patrimoine, les activités culturelles et la création artistique sont ainsi mises en avant à l'échelle du quartier et doivent servir la rénovation urbaine. $\mathrm{Ne}$ peut-on pas y voir les signes d'un modèle urbain alternatif où l'ensemble des démarches, des projets cherchent à organiser un développement urbain en se plaçant dans une perspective bottom up (Douay et Prévot, 2016) ? Les œuvres contribuent désormais à la notoriété du quartier voir illlustrations 23 à 26 : œuvres de street art dans le quartier Vergini-Sanità) et alimentent les circuits touristiques, même si le street art n'est pas un "produit» proposé et vendu par la Paranza en tant que tel. Outil de marketing et de promotion des interventions menées par la Fondation, les fresques servent selon ces acteurs à renforcer le sens civique, réputé faible dans les quartiers populaires, et à combattre les clichés persistants.

Pourtant, le discours sur la requalification de l'espace porté par ces acteurs urbains suscite une inégale appropriation et adhésion : des polémiques sont ainsi nées dès 2017 suite à la multiplication des interventions artistiques dans le quartier (Senna, Collectif FX). La valorisation du street art n'est pas systématiquement acceptée par l'ensemble 
des associations culturelles et provoque souvent l'indifférence de la population. La dimension esthétique liée au réaménagement des places a aussi des effets limités. En définitive, cette valorisation du street art accompagne un processus de requalification du patrimoine et de valorisation touristique de l'ensemble de l'aire portée par les acteurs du territoire (Salomone, 2016). Elle est désormais encouragée par les actions de la municipalité.

Illustration 23a - Fresque de Bosoletti, Place San Severo complétée par les productions des habitants

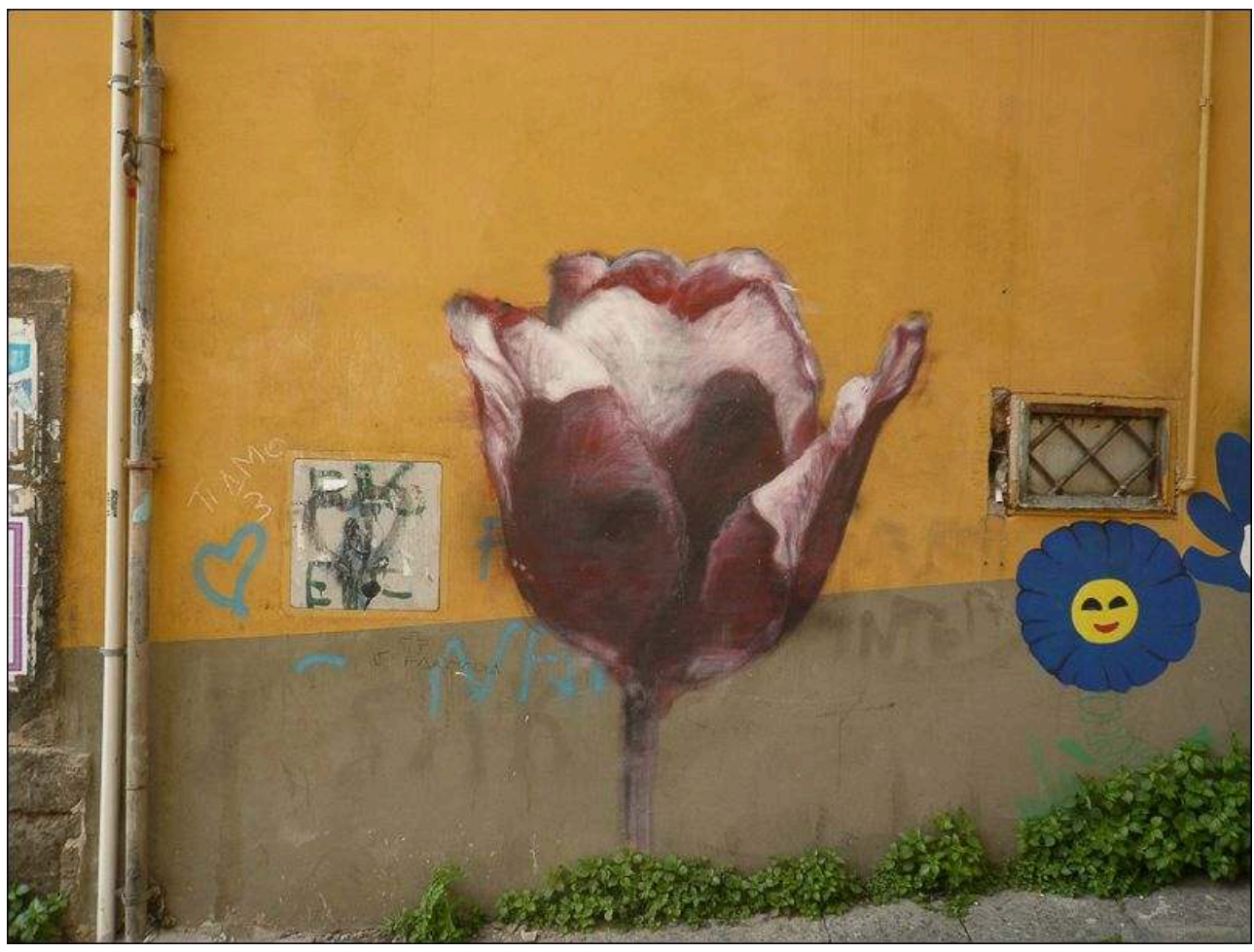

Auteur: C. Salomone, 2017. 
Illustration 23b - Fresque de Bosoletti, Place San Severo complétée par les productions des habitants

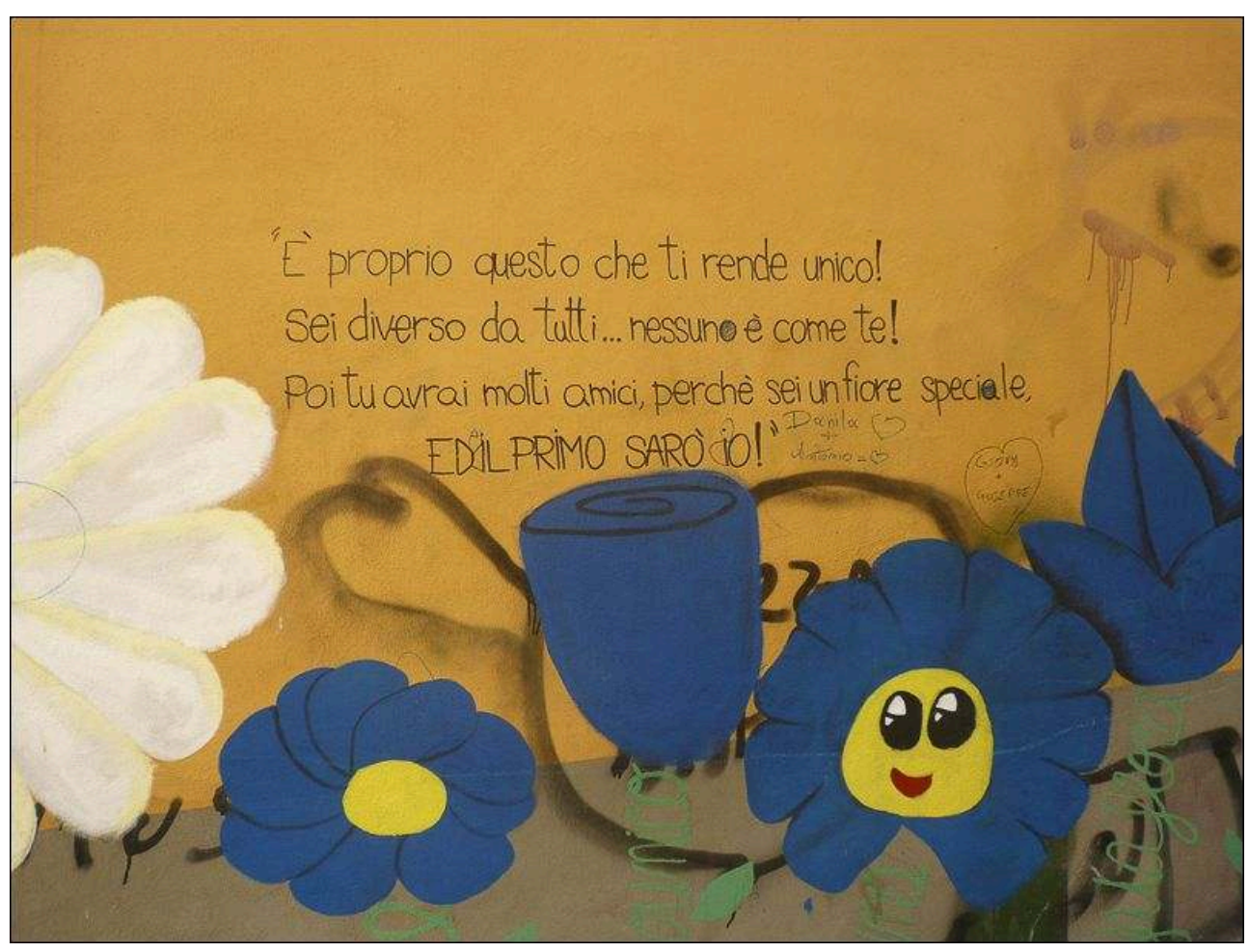

Auteur : C. Salomone, 2017.

Illustration 24 - Fresques de Mono Gonzales sur la façade de l'église des Fontanelle

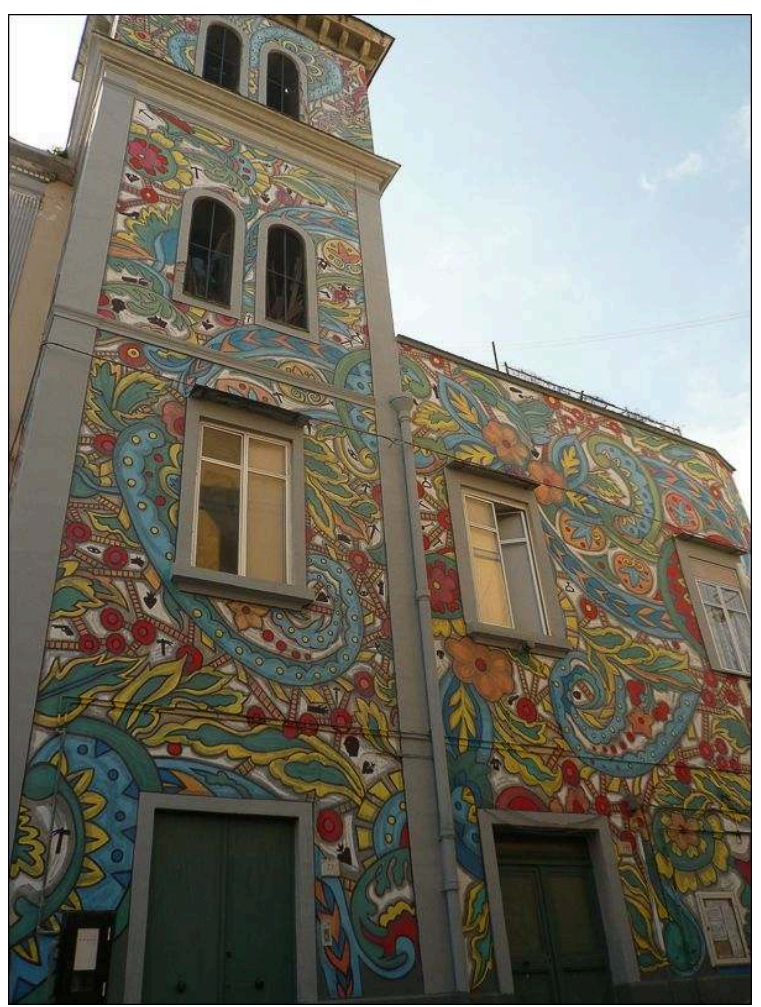

Auteur: C. Salomone, 2017. 
Illustration 25 - Fresques « Speranza Nascosta » (espérance cachée) à l'entrée du centre pour SDF, La Tenda

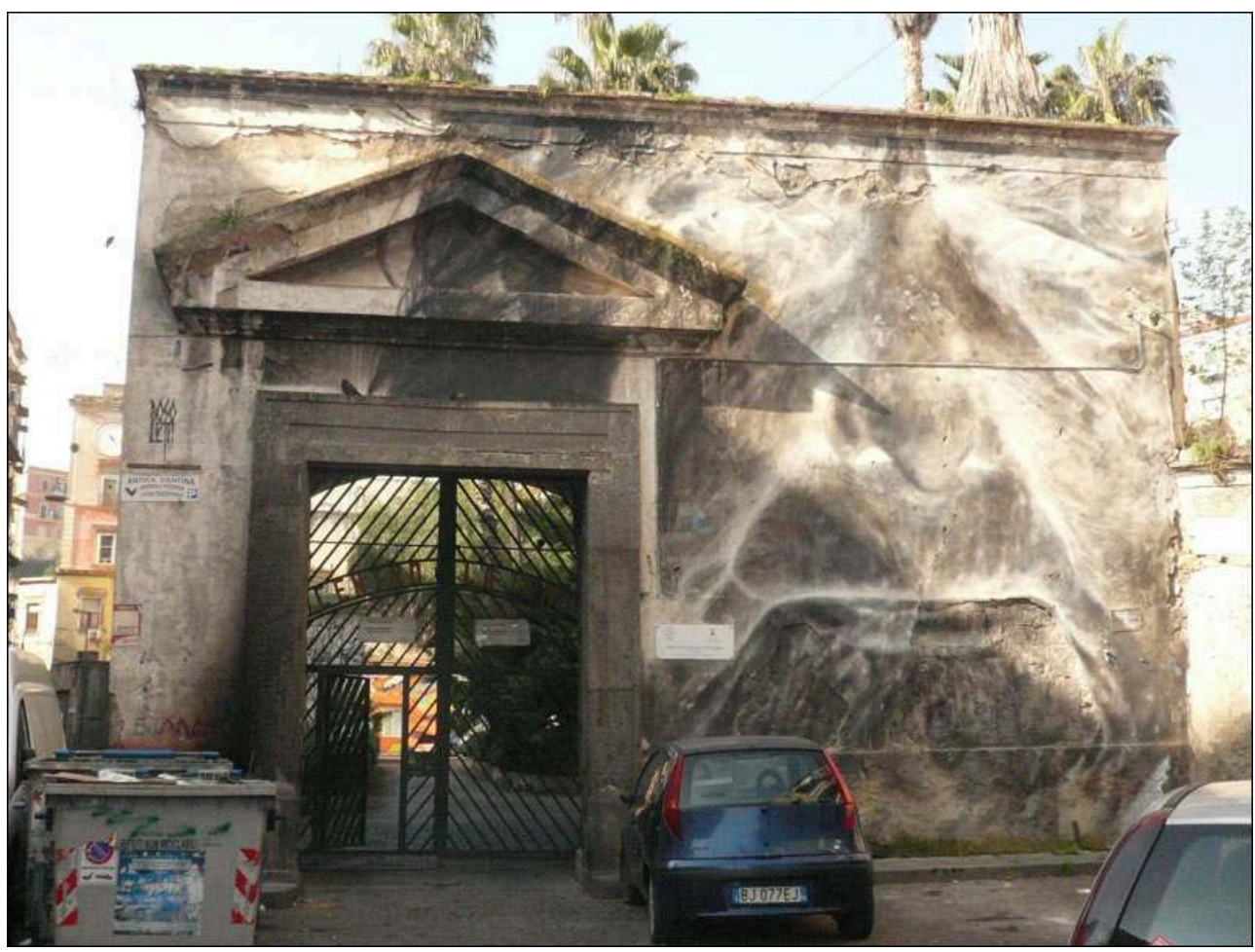

Auteur : C. Salomone, 2017.

Illustration 26 - Fresque de F. Bosoletti, « Resis-ti-amo »

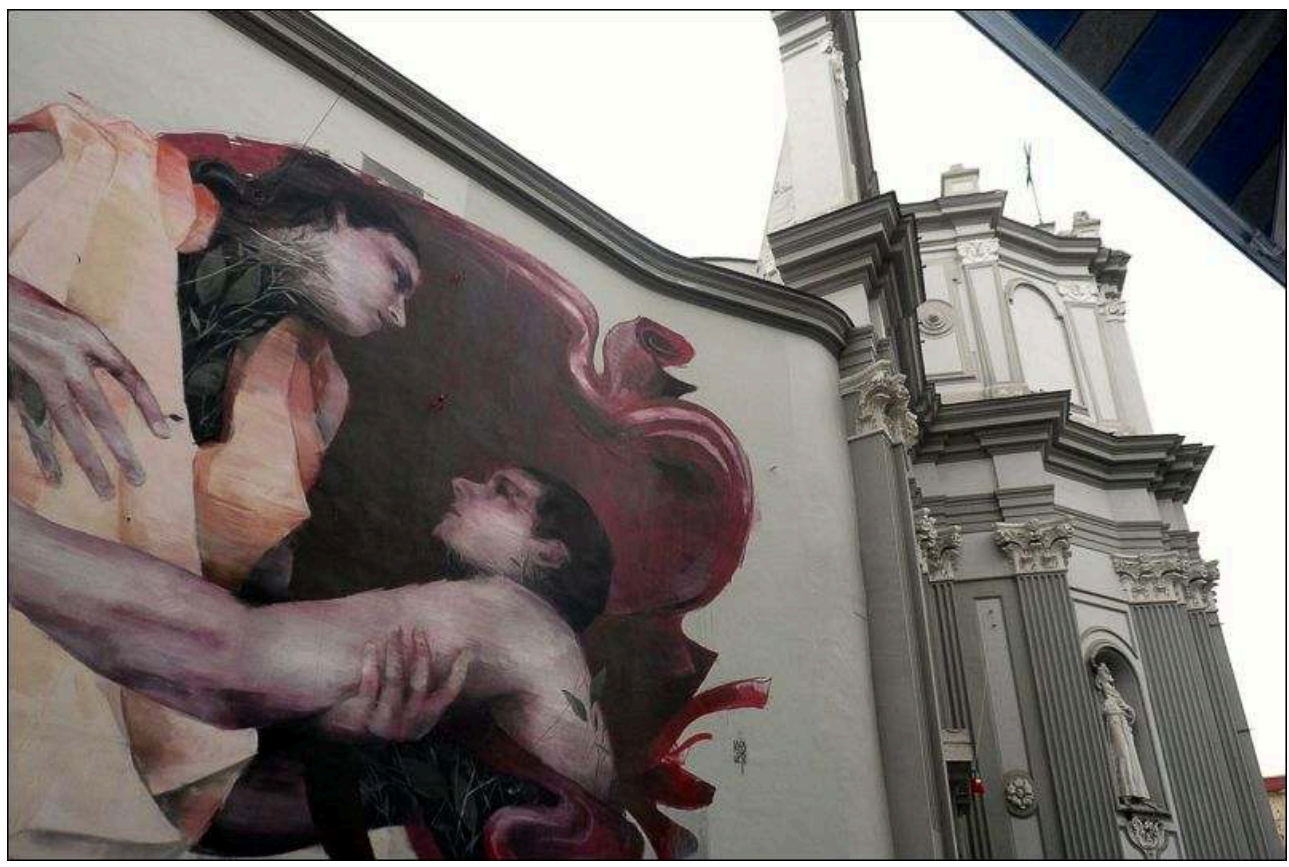

Auteur : C. Salomone, 2016. 


\section{Des initiatives relayées par la commune : vers une instrumentalisation du street art?}

Le street art, perçu «comme un puissant vecteur de modernité, à cheval entre communauté sociale et monde de l'art, offrant un potentiel touristique considérable ${ }^{38}$, a su susciter l'intérêt de la nouvelle municipalité élue en 2011 (entretien avec S. Ascione, membre du staff à l'Assessorat aux jeunes, mars 2018). Les financements publics (municipaux, régionaux et européens) sont mobilisés pour soutenir des interventions artistiques contribuant à la requalification urbaine de quartiers dégradés ou pour développer des actions de sensibilisation et d'éducation auprès de la population (Amato, 2015). Pour répondre à la profusion des œuvres apparues sur les murs de Naples, la municipalité favorise l'expression de cet art urbain et se dote d'un pacte «street art-biens communs » réglementant l'utilisation des espaces urbains. Elle prolonge ainsi les initiatives menées dans le cadre des procédures d'adoption et de gestion des espaces publics ${ }^{39}$ (Salomone, 2018, à paraître). Elle veut contribuer à changer l'image des lieux, en particulier dans les territoires périphériques, et à favoriser une appropriation des espaces publics. Le street art est mobilisé et instrumentalisé. Au-delà de la démarche esthétique, il revêt une dimension citoyenne et politique. D'où la nécessité d'une implication des habitants dans ces projets d'art participatif à travers la réalisation d'ateliers et de laboratoires :

«Dans l'idée que l'ensemble de la ville appartient à tout le monde, nous souhaitons qu'il y ait la participation de tous les citoyens à faire que les lieux, en particulier ceux plus dégradés et confrontés à des difficultés sociales soient pris en main parce qu'il faut donner cette dimension; (...) puis se développe ainsi une plus grande identité, un plus grand sentiment d'appartenance au quartier et au territoire » (entretien avec Renata Cianella, Assessorat à l'Urbanisme, février 2017).

37 À ses yeux, cet art urbain fait désormais partie de l'offre culturelle et peut faire naître de nouveaux circuits touristiques en périphérie ou dans les quartiers marginalisés du centre $^{40}$. Mais, faute de financements, la Commune doit accepter la mise en place d'une nouvelle gouvernance dans ce champ culturel où les initiatives sont portées par un tissu associatif dynamique et éclaté, tout en tentant de conserver un contrôle des procédures d'occupation des espaces publics. Le street art sert le discours officiel sur la créativité, l'innovation et l'impératif participatif. Les associations, impliquées précocement dans la valorisation du street art, ont contribué à sa reconnaissance dans un contexte qui valorise la créativité. Toutefois, certains de ces acteurs " historiques » (INWARD, Napoli Paint Stories) sont désormais très critiques à l'égard des propositions ${ }^{41}$ institutionnelles et refusent l'idée de ce "pacte street art-biens communs ». La démarche est jugée contraire à la liberté de création et contradictoire avec la spontanéité des artistes. On refuse indirectement le nouveau rapport de force qui s'établit entre ces acteurs du champ culturel et le jeu de pouvoir.

\section{Conclusion}

Naples, ville méditerranéenne fragilisée par la crise économique et le désengagement des acteurs publics dans le champ culturel, apparait comme un véritable laboratoire 
d'expérimentations sociales où le tiers secteur participe activement à sa renaissance par le biais de la culture. La reconnaissance de cet art urbain comme un art à part entière se vérifie aujourd'hui avec la politique municipale en faveur de la créativité urbaine ou les initiatives de certains musées. Sa valorisation et sa promotion relèvent avant tout d'initiatives individuelles et associatives nées de la société civile, investissant ce champ culturel, avec des objectifs variés et dans des contextes territoriaux spécifiques. Dans des quartiers fragiles comme la Sanità ou Ponticelli, les acteurs associatifs en font un instrument de reconquête du territoire: œuvres d'intégration sociale, les projets artistiques tentent de modifier le regard porté sur ces quartiers et s'efforcent de recréer du lien social. Le street art est présenté comme un outil au service du renouvellement urbain dans des quartiers en déshérence.

Dans les deux exemples étudiés, la valorisation du street art répond à un art " officialisé ", à des pratiques «in" où les artistes ont été pris en charge pour la réalisation de leurs œuvres dans un cadre autorisé et légal. La reconnaissance et la notoriété publique des interventions aboutissent à une forme d'intégration de cet art urbain, auquel les acteurs ont assigné un rôle précis. La création artistique est instrumentalisée dans les quartiers périphériques, elle témoigne d'enjeux politiques et symboliques. Dans les quartiers plus centraux (Sanità), les interventions accompagnent un processus de requalification du patrimoine et de valorisation touristique et constituent une nouvelle « ressource » pour le territoire. En cela, ces interventions se différencient totalement des initiatives spontanées et souvent illégales menées dans les Quartiers espagnols ou à Gianturco. Mais la frontière est tenue, car ces mêmes artistes impliqués dans des créations "officielles" n'ont pas totalement rompu avec des pratiques performatives transgressives. La réalité du street art révèle des situations aux contours flous et une hybridation des pratiques in et off.

L'intégration peut également s'effectuer à travers la mise en tourisme du street art : à Naples, elle demeure balbutiante et relève d'une offre émergente, faiblement professionnalisée, qui s'inscrit dans le cadre d'un tourisme alternatif voire expérientiel. Les circuits de découverte privilégient les espaces du centre historique ou explorent des quartiers perçus comme authentiques et créatifs, plus rarement les périphéries, pourtant terrain privilégié de cette forme d'expression. La mise en tourisme est aussi encouragée par la commune, qui perçoit le street art comme un vecteur d'innovation et de créativité. Le soutien apporté aux projets culturels dotés d'une dimension participative permet ainsi de dynamiser l'image de la ville. Outil de marketing, cet art urbain doit contribuer à la mise en scène des espaces en mutation. Sa valorisation s'opère dans le cadre de la politique en faveur de la créativité urbaine. La municipalité prolonge ainsi son engagement en faveur de la politique des biens communs. Mais cela suppose d'établir une nouvelle gouvernance avec les acteurs associatifs ou privés: entre autonomie, liberté de création et volonté de réglementation. Les résistances sont encore nombreuses parmi les artistes ou les promoteurs de la valorisation du street art. On peut dès lors s'interroger sur les limites ou les contradictions d'une politique culturelle, privée de ressources financières, qui semble vouloir "récupérer " un art urbain profondément hybride et souvent transgressif. 


\section{BIBLIOGRAPHIE}

Amato Fabio, 2015. Il lungo dialogo tra arte e geografia. Il paesaggio urbano in transformazione : $\mathrm{i}$ murales nei quartieri disagiati di Napoli. Estetica. Studi e ricerche, 2/2015, Aracne editrice, p. 7-17.

Ambrosino C., Guillon V., 2014. Les tournants culturels des sociétés urbaines. In G. Djament-Tran et P. San Marco (dir.), La métropolisation de la culture et du patrimoine. Paris, Éditions Le Manuscrit, p. 55-71.

Andres L., Ambrosino C., 2008. Régénération culturelle et mutabilité urbaine : un regard francobritannique. In F. Leriche et al. (ed.), L'économie culturelle et ses territoires. Toulouse, Presses universitaires du Mirail, p.305-317.

Antonioli G., 2015. Arte Pubblica a Torino. Dal 1995 al 2015. Venezia, Università Cà Foscari, Tesi di Laurea magistrale in Storia delle Arti e Conservazioni dei Beni artistici, 225 p.

Authier J.-Y., Bidou-Zachariasen C. (dir.), 2008. La gentrification urbaine. Espaces et Sociétés, $n^{\circ} 132-133$

Bianchini F., Parkinson M. (dir.), 1993. Cultural Policy and Urban Regeneration. The West European Experience. Manchester and New York, Manchester University Press, $224 \mathrm{p}$.

Blanchard S., 2017. Street art, rénovation urbaine et gentrification dans le Nord- est parisien entre marketing urbain et gender mainstreaming. Urbanités [En Ligne], $\mathrm{n}^{\circ}$ 9. http://www.revueurbanites.fr/9-street-art-renovation-urbaine-et-gentrification-dans-le-nord-est-parisien-entremarketing-urbain-et-gender-mainstreaming/

Blanché U., 2015. Qu'est-ce que le street art ? Essai et discussions des définitions, Cahiers de Narratologie [En ligne], 29. http://journals.openedition.org/narratologie/7397

Bourgeon D., Bouchet P., 2007. Marketing expérientiel et analyse des logiques de consommation du spectacle sportif. Revue française du marketing, $\mathrm{n}^{\circ} 212$, p. 87-101.

Cattedra, R., Memoli, M., 2003. La réappropriation du patrimoine du centre historique de Naples. In C. Bidou-Zachariasen (dir.), Retours en ville. Des processus de « gentrification » urbaine aux politiques de « revitalisation » des centres. Paris, Descartes et Cie, p. 147-169.

Chabrol M., Collet A., Giroud M., et al., 2016. Gentrifications. Paris, Éditions Amsterdam, 357 p.

Clerval A., Fleury A., 2009. Politiques urbaines et gentrification, une analyse critique à partir du cas de Paris. L'Espace politique, [En ligne], 8 | 2009-2. http://journals.openedition.org/ espacepolitique/1314

Connaître le Street art, 2017. Connaissance des arts, Hors- série n 751 . Paris, SFPA, 98 p.

Dines N., 1999. Centri sociali : occupazioni autogestite a Napoli negli anni novanta. Quaderni di sociologia, $\mathrm{n}^{\circ} 21$, p. 90-111.

Djament-Tran G., 2014. Introduction Déconstruire la « ville créative » pour analyser la fabrique métropolitaine de la culture / la fabrique culturelle de la métropolisation. In G. Djament-Tran, et P. San Marco, La métropolisation de la culture et du patrimoine. Éditions Le Manuscrit, p 7-25.

Douay N., Prévot M., 2016. Circulation d'un modèle urbain « alternatif » ?, Echogéo [En Ligne], 36. http://journals.openedition.org/echogeo/14617

Fagnoni E., Gravari-Barbas M., 2013. Métropolisation et Tourisme : Comment le tourisme redessine Paris. Paris, Belin, 320 p. 
Festa D., 2012, Dalla rete di cittadini attivi all'occupazione dell'Ex-Cinema Palazzo : verso uno spazio pubblico. In Atti della Biennale dello Spazio Pubblico, Urbanistica Informazioni. Rome, INU Edizioni, p. 239-240.

Festa D., 2016. Les communs urbains. L'invention du commun. Tracés. Revue de Sciences humaines [En ligne], $\mathrm{n}^{\circ} 16$. http://journals.openedition.org/traces/6636

Fleury A., Froment-Meurice M., 2014. Embellir et dissuader : les politiques d'espaces publics à Paris. In A. Da Cunha et S. Guinand, Qualité urbaine, justice spatiale et projet. Ménager la ville. Lausanne, Presses polytechniques et universitaires romandes, p. 67-79.

Froment P., 2003a. Les espaces publics dans les politiques patrimoniales à Naples. Rives méditerranéennes, $\mathrm{n}^{\circ} 16$, p. 99-118.

Froment P., 2003b. La renaissance de Naples-Réussites et ambiguïtés, Cahier Espaces, Editions touristiques Européennes, $n^{\circ} 78$, p.36-46.

Froment P., 2010. Art contemporain et territoires urbains : le musée MADRe à Naples. Méditerranée, n 114, pp. 103-112.

Froment P., 2015. Villes méditerranéennes en clairs-obscurs. De l'artisan à l'artiste ? Trajectoires et modèles. HDR, Université de Paris 7.

Froment P., 2016. Lieux culturels et informalité politique à Naples, une approche par les pouvoirs multi-situés. L'Espace politique, vol 29, n 2, p.1-20.

García B., 2004. Urban Regeneration, Arts Programming and Major Events: Glasgow 1990, Sydney 2000 and Barcelona 2004. International Journal of Cultural Policy, vol. 10, n 1, p. 103-116.

Génard J.-L., 2014. Cultures urbaines et politiques culturelles. SociologieS, Dossiers, Diversification artistique et politiques culturelles, [En ligne]. http://journals.openedition.org/sociologies/4575

Genin C., 2008. Miss.Tic : Femme de l'être. Bruxelles, Les Impressions nouvelles, 208 p.

Genin C., 2015. Le street art : de nouveaux principes ? Cahiers de Narratologie [En ligne], 29. http:// journals.openedition.org/narratologie/7396

Genin C., 2016. Le street art au tournant, De la révolte aux enchères. Paris, Les impressions nouvelles, $258 \mathrm{p}$.

Gilabert T., 2004. La géographie de l'art contemporain en France. Thèse de doctorat, Université de Nantes, $533 \mathrm{p}$.

Gombeau A., 2011. Tourisme et création : les hypermodernes. Mondes du tourisme, Varia, $\mathrm{n}^{\circ} 4$, p. 18-35.

Gravari-Barbas M., 2009. La 'ville festive' ou construire la ville contemporaine par l'événement. Bulletin de l'Association des géographes français (BAGF), $\mathrm{n}^{\circ}$ 3, p. 279-229.

Gravari-Barbas M., 2013. Aménager la ville par la culture et le tourisme. Paris, Éditions Le Moniteur, $157 \mathrm{p}$.

Gravari-Barbas M., Delaplace M., 2015. Le tourisme urbain « hors des sentiers battus ». Téoros [En Ligne], vol. 34, $\mathrm{n}^{\circ}$ 1-2. http://journals.openedition.org/teoros/2790

Gresillon B., 2014. Qu'est-ce qu'une métropole culturelle ? In G. Djament-Tran, et P. San Marco, La métropolisation de la culture et du patrimoine. Éditions Le Manuscrit, p. 29-54.

Hall P., 1998. Cities in civilization. New-York, Pantheon Books, 1169p.

Heinich N., Shapiro R. (dir.), 2012, De l'artification. Enquêtes sur le passage à l'art. Paris, EHESS, 336 p. 
Ingallina P., Park J., 2005. Les nouveaux enjeux de l'attractivité urbaine. Urbanisme, $\mathrm{n}^{\circ} 344$, p. 66-68.

Kullmann C., 2015. De l'exposition de la Tour Paris 13 au concept de musée à ciel ouvert. Téoros, [En Ligne], vol. 34, n 1-2. http://journals.openedition.org/teoros/2776

La Rocca F., 2013. La ville dans tous ses états. Paris, CNRS, 354 p.

Lebeau B., 2014. Une « banlieue créative » dans le Grand Paris ? EchoGéo [En Ligne], n² 27. http:// journals.openedition.org/echogeo/13718

Lextrait F., Kahn F., 2004. Nouveaux territoires de l'art. Paris, Sujet-Objet, 295 p.

Liebaut M., 2012. L'artification du graffiti et ses dispositifs. In De l'artification : Enquêtes sur le passage à l'art. Paris, Éditions de l'EHESS, p. 151-169.

Marin B., 2010. Naples. Paris, Citadelles \& Mazenod, 493 p.

Masboungi A. (dir.), 1999. Renouveler l'urbain. Revue Projet urbain, nº 18, p. 3-35.

Mastroianni R. (a cura di), 2013. Writing The City, Graffitismo, immaginario urbano e street art. Rome, Aracne, 284p.

McAuliffe C., 2012. Graffiti or Street art? Negotiating the Moral Geographies of the Creative City. Journal of Urban Affairs, vol. 34, n² 2, p.189-206.

McAuliffe C., Iveson K., 2011. Art and Crime (And other Thongs Besides...) Conceptualising Graffiti in the City. Geography Compass, vol. 5, n 3, p. $128-143$.

Miedo D., Schiavon D., 2016. Palude. Naples, Monitor Edizioni, 84 p.

Milliot V., 2000. Quand l'art interroge l'espace public. Le graff, le travail social, l'art contemporain et le politique. In J.-P. Saez et T. Raspail (dir.), L'art contemporain, champs artistiques, critères, réception. Actes du colloque l'Art sur la Place. Paris, L'Harmattan, p. 179-195.

Novarina G., Pucci P., 2004. Renouvellement en France, requalification en Italie : formes récentes du partenariat public-privé. Les Annales de la Recherche Urbaine, nº 97, p. 83-91.

Palestino M.F., 2003. Miranapoli. La costruzione dell'immagine urbana negli anni " 90 ". Naples, Clean Napoli, 112 p.

Pappalepore I., Maitland R., Smith A., 2010. Exploring Urban Creativity: Visitor Experiences of Spitalfields, London. Tourism, Culture and Communication, vol. 10, n 3, p. 217-230.

Petrillo A., 2011. Napoli Globale: discorsi, territorio e potere nella « città plebea ». In S. Palidda (a cura di), Città mediterranee e deriva liberista. Messina, Edizioni Mesogea, p. 45-70.

Ramella R., 1995. Mobilitazione pubblica e società civile meridionale. Meridiana, n²2-23, p. 121-154.

Richards G., Wilson J., 2006. Developing creativity in tourist experiences: A solution to the serial reproduction of culture. Tourism Management, vol. 27, p. 1209-1223.

Richards G., 2011. Creativity and Tourism: The State of the Art. Annals of Tourism Research, vol. 38, no 4 , p. 1225-1253.

Rodrigues-Malta R., 2001. Régénération urbaine : variations sud-européennes. L'Information Géographique, vol. 65, n 4, p. 321-339.

Rossi U., 2009. Spazio conteso. Il centro storico di Napoli tra coalizione e conflitti. Naples, Guida editore, $212 \mathrm{p}$. 
Rousseau M., 2014. Redéveloppement urbain et (in)justice sociale : les stratégies néolibérales de « montée en gamme » dans les villes en déclin. Justice spatiale / Spatial justice [En Ligne], nº 6. http://www.jssj.org/article/redeveloppement-urbain-et-injustice-sociale-les-strategiesneoliberales-de-montee-en-gamme-dans-les-villes-en-declin/

Saez G., 2014. La métropolisation de la culture. Cahiers Français, nº 382, p. 10-15.

Salomone C., 2013. Patrimoine et valorisation touristique au cœur d'une tentative de requalification d'un quartier : le cas de la Sanità à Naples. Colloque ASRDLF, Culture, Patrimoine et Savoirs. Mons, juillet 2013.

Salomone C. 2015. La Naples souterraine et le tourisme de l'insolite où comment réinventer une destination traditionnelle? Téoros [En Ligne], vol. 31, $\mathrm{n}^{\circ}$ 1-2. http://journals.openedition.org/ teoros/2787

Salomone C, 2016. The Sanità district in Naples: Community involvement in developing its heritage value. Proceedings of the 7th International Conference on Sustainable Tourism, Wit Transactions on Ecology and the Environment, vol. 201, p. 223-231.

Salomone C., 2018. Stratégies d'acteurs et nouvelles pratiques spatiales au cœur de la requalification d'un quartier populaire du centre historique de Naples : l'aire Vergini-Sanità. Méditerranée, (à paraître).

Talamoni R., 2015, Les stratégies de mise en valeur du street art à Vitry sur Seine. Mémoire de master 2, UPEC, $110 \mathrm{p}$.

Tagliazucchi E., 2013. La street art in Italia.Problemi giuridici tra arte e tutela dello spazio urbano. Venezia, Tesi di Laurea, Università Cà Foscari, 120 p.

Tomassini M., 2012. Beautiful winners. La street art tra underground, arte e mercato. Verona, Ombre Corte, $220 \mathrm{p}$.

Trigilia C. (a cura di), 1995. Cultura e sviluppo. L'associazionismo nel Mezzogiorno. Rome, Donzelli, 258p.

Throsby D., 2001. Economics and Culture. Cambridge, Cambridge University Press, 208 p.

Velter A., 2014. Ernest Pignon-Ernest. Paris, Gallimard, 357 p.

Vivant E., 2007. Les événements off: de la résistance à la mise en scène de la ville créative. Géocarrefour, vol. 82, n³, pp. 131-140.

Vivant E., 2009. Qu'est-ce que la ville créative ? Paris, PUF, 96 p.

\section{NOTES}

1. INWARD, Econote, Travel Naples, Napoli Paint Stories, Vascitour, Tour Angels, la Paranza, Arginalia.

2. Cela supposerait un autre travail d'enquête et d'entretiens en prolongement auprès des populations concernées.

3. Les outils quantitatifs et indicateurs chiffrés pour mesurer le succès de cette offre touristique sont insuffisants. Les acteurs communiquent difficilement les chiffres de fréquentation des visites guidées.

4. Dans le cadre d'un autre travail de recherche mené par l'auteur, l'utilisation des réseaux sociaux par les catacombes de Naples et l'analyse des avis postés par les visiteurs ont été 
appréhendées à travers une analyse qualitative (analyse de contenu et utilisation du logiciel Nvivo) permettant d'étudier ces discours.

5. La dimension physique est regroupée sous le terme de "régénération urbaine " alors que le concept de renouvellement urbain renvoie à des politiques urbaines menées à l'échelle du quartier et prend en compte des dimensions sociale et économique. La vision globale à l'échelle de la ville peut se traduire par le terme de « ville renouvelée » (Masboungi, 1999).

6. Une chercheuse de l'Université de Bologne F. Allinovi porte son attention dans les années 1980 sur les writers de New-York. Elle organise à Bologne en 1982 une première exposition, qui fait connaître les artistes d'Outre-Atlantique. À sa mort en 1983, la Galerie d'art moderne fait venir des grands noms de la scène new-yorkaise.

7. La notion peut aussi être entendue dans un sens plus large englobant les processus de renouvellement social et de transformation du bâti (Authier et Bidou-Zachariasen, 2008) où les pouvoirs publics peuvent jouer un rôle important dans le processus en contribuant fortement à définir les règles du jeu (Chabrol et al., 2016).

8. À Poggioreale, on fait appel à l'architecte japonais Kenzo Tange pour édifier le nouveau centre directionnel dans les années 1980. Le projet modifie profondément la skyline de la ville (Froment, 2010) et apparaît comme un véritable corps étranger, disproportionné par rapport au reste du panorama urbain (Marin, 2010).

9. Une fondation créée en 1984 par des intellectuels et «bourgeois éclairés » (Rossi, 2010) dont l'objectif est la valorisation et la connaissance du patrimoine artistique napolitain grâce à des partenariats privés- publics (entretien avec la présidente de la fondation Mirella Barracco, 4 mai 2012).

10. Street artiste, originaire de Rome née en 1980 dont les œuvres sont aussi présentes notamment à Rome, Berlin et Londres.

11. Unique production de Bansky en Italie. Une seconde intervention avait été réalisée dans la via San Benedetto, mais elle fut détruite en 2009 et recouverte par l'œuvre d'un artiste napolitain.

12. Mr Chat séjourne à Naples en juin 2015 et il multiplie ses interventions sur des devantures de commerce en particulier dans un quartier populaire du centre où il réside (via San Apostoli) suite à la demande des commerçants (entretien commerçant, février 2018).

13. Un street artiste français originaire de Rennes. Il séjourne à Naples dès 2012, où il participe à un projet Fragiles Fabulae, avec une série d'images d'inspiration symboliste ou pré-raphaélienne réalisées dans plusieurs lieux centraux : Santa Chiara, Piazza Bellini et dans des quartiers plus marginaux (Palais Sanfelice dans le quartier Sanità) ou plus périphériques. Voir http:// www.napolike.it/intervista-a-zilda-street-artist

14. Un commerçant décide de financer la protection de la «Vierge au Pistolet » par une vitrine et d'y apposer une inscription. L'œuvre reconnue, identifiée et protégée devient un « incontournable » des circuits de visite.

15. Leur existence est attestée en Italie depuis les années 1970 dans un contexte socio-politique mouvementé (Dines, 1999).

16. Au début des années 2000 , le Ska est au cœur du mouvement de contestation contre la mondialisation (Rete no global) avant de connaître une véritable « crise d'identité » (Rossi, 2009). Il reste un symbole de ces combats politiques passés.

17. Sept lieux sont reconnus comme des biens communs: villa Medusa et l'ex- Lido Pola à Bagnoli, l'ex-Opg (monastère S. Eframo nuovo) et le jardin libéré à Materdei, l'ex-conservatoire Santa Fede Liberata, l'ex-Scugnizzo Liberato et l'ex-Asilo Filangieri, l'ex-Schipa à Salvator Rosa.

18. Pour compléter ces discours, il faudrait également interroger d'autres artistes qui agissent dans l'espace urbain en acceptant d'être financés et de servir une "commande "; les contours sont parfois poreux entres les conduites et les pratiques artistiques.

19. Les trois artistes sont originaires de Naples et sa province, ils ont entre 30 et 40 ans et ont commencé leurs interventions dans les années 1990 Ils ont aujourd'hui diversifié leurs activités. 
Le duo Cyop and Kaf anime une maison d'édition, édite un journal mensuel le Napoli Monitor et réalise des productions artistiques sur d'autres supports. Gennaro Maria Cedrangolo est membre d'une crew importante de Naples (il a tenu à conserver son anonymat d'artiste); membre fondateur et président de $400 \mathrm{ml}$, il gère l'association Napoli Paint Stories engagée dans la promotion et la valorisation du street art. Diego Miedo, artiste engagé, conserve une démarche à dominante transgressive (lien avec les centres sociaux occupés) ; ses œuvres sont essentiellement localisées à Naples et en province; il s'engage aussi dans des projets avec des établissements scolaires.

20. Désormais, le duo a cessé ses activités nocturnes et clandestines (trains, graffitis) et expose parfois dans des galeries en Italie et à l'étranger.

21. Il est proche du dépôt des trains et du centre social occupé Officina 99.

22. Le duo d'artistes évoque des échanges violents par le passé avec cet opérateur (INWARD) ; les deux artistes critiquent ouvertement ces propositions perçues comme une tentative d'élaborer avec le gouvernement une forme de réglementation officielle pour encadrer les pratiques.

23. Le travail achevé en 2013 par le duo d'artistes s'accompagne de la publication d'un ouvrage à compte d'auteurs en tirage limité (500 exemplaires) « Q.S, Quore Spinato ».

24. Un habitant des Quartiers espagnols, ayant suivi les interventions artistiques de Cyop and Kaf a mis sur pied un «tour» dans le quartier soutenu initialement par les deux artistes (Hermes turismo e Bene culturali).

25. Federica Belmonte, ayant effectué un mémoire sur Bansky est à l'origine de ce premier circuit de visites guidées dans le centre historique.

26. Né dans le cadre de l'initiative «NAU Naples action urbaine », il relève du programme des «Plans locaux Jeunes-Cité métropolitaine» soutenus par le Département de la jeunesse, la Présidence du Conseil des Ministres et l'Association Nationale des Communes italiennes.

27. En 2014, la ville de Naples a financé pour plus d'un 1,9 millions d'euros des projets favorisant la créativité urbaine et la jeunesse.

28. Repas chez les habitants, rencontre avec les habitants dans les quartiers populaires du centre historique pour "découvrir la mémoire du lieu et celle des habitants » ou encore hébergement dans les « bassi », logements populaires typiques de Naples chez Vascitour.

29. Regroupant $31 \%$ de la population de la III $^{\mathrm{e}}$ municipalité, ce quartier compte près de 32000 habitants répartis sur un territoire de $2 \mathrm{~km}^{2}$.

30. L'Observatoire a connu une évolution complexe à partir de l'expérience de jeunes créatifs issus du monde du rap, du hip hop et du street art dans les années 1990. En 2004, le projet Circumwriting mené avec l'entreprise de transport de la Circumvesuviana fait naître l'association Arteteca qui se dote d'un observatoire pour la créativité urbaine INWARD. Ce dernier collabore avec la présidence du Conseil des ministres au sein d'une table technique sur la créativité urbaine de 2008 à 2011.

31. L'Observatoire né à Naples, occupe un local situé au-dessus d'une station de la Circumvesuviana à Ponticelli. Aujourd'hui, il soutient de nombreux projets liés à la créativité urbaine dans toute l'Italie.

32. Les œuvres sont celles d'artistes italiens et napolitains (Jorit, Rosk and Loste, Zed I, la fille Bertha, Mattia Campo dell'Orto et Hope).

33. Association culturelle créée en 2014 organisant des visites guidées à Naples et dans les environs (trekking urbain, parcours sur le Vésuve et circuits à Ponticelli). $40 \%$ des circuits proposés par l'association concernent le street art.

34. INWARD a néanmoins signé un accord avec la GESAC, l'organisme gestionnaire de l'aéroport de Naples qui a décidé de médiatiser l'expérimentation sur son site internet, tout comme le portail d'information touristique « visitnaples.eu ».

35. Le quartier présente des dynamiques touristiques fortes: multiplication des B\&B et des appartements en location à destination des touristes, hausse de la fréquentation dans les divers 
sites, image revalorisée dans les guides touristiques et magazines culturels (Salomone, 2016). Ces dynamiques sont porteuses d'un processus de gentrification dans un quartier proche du centre antique et en pleine effervescence culturelle.

36. On peut difficilement évaluer le nombre de personnes concernées, mais ce chiffre demeure infime au vu des densités habitantes de l'aire Vergini-Sanità.

37. La III ${ }^{\mathrm{e}}$ municipalité est dirigée par Ivo Poggiani, qui est proche des jeunes de la Paranza et de la Fondation de Communauté. Dans ses prises de position, il apparaît comme un soutien indéfectible à ces acteurs du territoire (entretien, le 23 février 2017).

38. Site internet de la Commune de Naples.

39. Suite à l'adoption de trois règlements en conseil communal en 2016.

40. En mai et juin 2018, la municipalité encourage des «tours» organisés par des associations locales du quartier Sanità autour du cinéma et du street art dans le cadre du projet Adolescents en art.

41. Luca Borriello dans un échange informel (février 2018) explique avoir été " court-circuité » par la commune. Il a participé aux premières réunions de la table inter-institutionnelle, puis estime avoir été mis à l'écart. Les relations sont devenues plus distantes.

\section{RÉSUMÉS}

Cet article étudie le rôle du street art dans les transformations urbaines d'une ville du sud de l'Italie, Naples, et sa difficile valorisation. Terreau fertile et emblématique de cet art urbain avec des expériences artistiques précoces dès les années 1980, Naples ne figure pourtant pas dans les grandes destinations du street art comme Berlin, Barcelone ou Londres. Alors que d'autres villes d'Italie comme Rome ou Milan réfléchissent à de nouveaux instruments et outils de valorisation touristique du street art, la ville peine à faire émerger officiellement cette offre. Pourtant les initiatives spontanées ou non en faveur de l'art urbain issues de quartiers variés - marges du centre historique ou quartiers plus périphériques - se sont étoffées et densifiées. Aux côtés des artistes, les promoteurs de l'art urbain sont pluriels (privé, associatif et institutionnel). Ils investissement ce champ de la culture avec des objectifs variés pour en faire notamment un outil au service du renouvellement urbain et de la créativité dans des quartiers en déshérence. Pour envisager cette articulation entre valorisation du street art et espace urbain, l'article confronte les initiatives privées dans deux quartiers napolitains, une marge du centre historique, l'aire Vergini-Sanità et un quartier plus périphérique, Ponticelli. Il interroge les discours et le jeu des acteurs et questionne la nature des espaces valorisés et les objectifs recherchés.

This article studies the role of street art in the urban transformation of a city in southern Italy, Naples, and its difficult valorisation. Fertile and emblematic soil of this urban art with early artistic experiences as early as the 1980s, Naples does not appear in the major street art destinations like Berlin, Barcelona or London. While other Italian cities such as Rome or Milan are thinking about new instruments and tools to promote street art tourism, the city is struggling to make this offer officially emerge. Yet spontaneous or non-spontaneous initiatives in favour of urban art from various neighbourhoods - at the margins of the historic centre or more peripheral neighbourhoods - have grown and become denser. Alongside artists, urban art promoters are plural (private, associative and institutional). They invest this field of culture with various objectives to make it a tool for urban renewal and creativity in deprived neighbourhoods. 
To envisage this articulation between the valorisation of street art and urban space, the article confronts private initiatives in two Neapolitan neighbourhoods, a margin of the historic centre, the Vergini-Sanità area and a more peripheral neighbourhood, Ponticelli. It questions the discourses and the play of the players and questions the nature of the valued spaces and the objectives sought.

\section{INDEX}

Keywords : street art, tourism players, urban renewal, creative tourism

Mots-clés : street art, acteur, tourisme, renouvellement urbain, tourisme créatif

\section{AUTEUR \\ CHRISTINE SALOMONE}

Christine Salomone, c19salomon@gmail.com, est docteure en géographie et chercheure associée au Laboratoire TVES, Université de Lille I (EA 4477). Elle a ou va publier :

- Salomone C., Haddouche H., Corbisiero F., (à paraître). Représentations des usagers et démarches d'apprentissages dans une aire marine protégée : le cas de la Gaiola à Naples. In $\mathrm{E}$. Peyvel, L'éducation aux voyages. Construction et circulations des savoirs. Presses Universitaires de Rennes.

- Salomone C., Haddouche H., 2018. Generation Z and Tourism experience: Tourist stories and Use of social Networks? The EFTI Journal of Tourism Futures, vol. 4, Issue 1, p 69-79. https://doi.org/ 10.1108/JTF-12-2017-0059

- Salomone C., 2016. The Sanità district in Naples: Community Involvement in developing its Heritage Value. WIT Transactions on Ecology and the Environment, Sustainable Tourism VII, vol. 201, p. 223-231. 